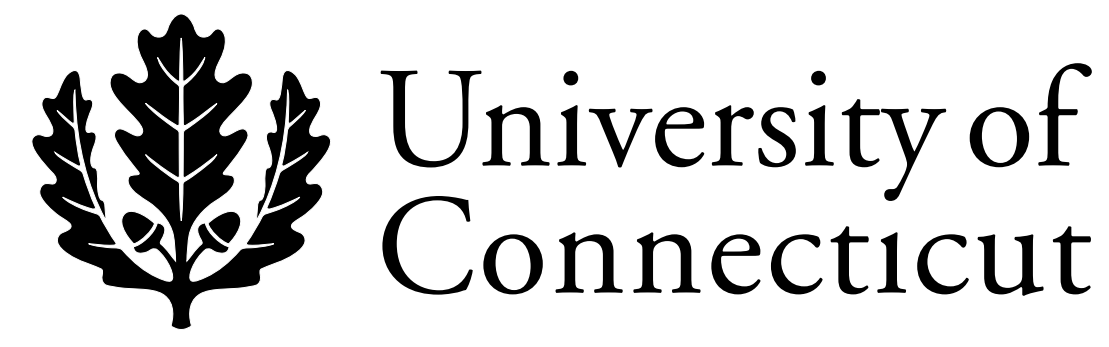

Department of Economics Working Paper Series

\title{
Human Capital and Interethnic Marriage Decisions
}

Delia Furtado

University of Connecticut

Working Paper 2006-03

February 2006

341 Mansfield Road, Unit 1063

Storrs, CT 06269-1063

Phone: (860) 486-3022

Fax: (860) 486-4463

http://www.econ.uconn.edu/

This working paper is indexed on RePEc, http://repec.org/ 


\begin{abstract}
Despite a longstanding belief that education importantly affects the process of immigrant assimilation, little is known about the relative importance of different mechanisms linking these two processes. This paper explores this issue through an examination of the effects of human capital on one dimension of assimilation, immigrant intermarriage. I argue that there are three primary mechanisms through which human capital affects the probability of intermarriage. First, human capital may make immigrants better able to adapt to the native culture thereby making it easier to share a household with a native. Second, it may raise the likelihood that immigrants leave ethnic enclaves, thereby decreasing the opportunity to meet potential spouses of the same ethnicity. Finally, assortative matching on education in the marriage market suggests that immigrants may be willing to trade similarities in ethnicity for similarities in education when evaluating potential spouses. Using a simple spouse-search model, I first derive an identification strategy for differentiating the cultural adaptability effect from the assortative matching effect, and then I obtain empirical estimates of their relative importance while controlling for the enclave effect. Using U.S. Census data, I find that assortative matching on education is the most important avenue through which human capital affects the probability of intermarriage. Further support for the model is provided by deriving and testing some of its additional implications.
\end{abstract}

Journal of Economic Literature Classification: J12, I21, J15

Keywords: Interethnic Marriage, Human Capital, Second-Generation Immigrants, Assimilation

I would especially like to thank Andrew Foster for his guidance and insightful comments. I am also grateful to Rachel Friedberg, Kaivan Munshi, and all of the seminar participants at Brown University, University of Connecticut, and the Institute for the Study of Labor (IZA) in Bonn, Germany. All remaining errors are my own. 


\section{Introduction}

The assimilation of immigrants has been an intensely debated topic both in academia and the media. The speed, measured in both years and generations, at which immigrants become indistinguishable from the native population has important implications for policies governing both the quantity and types of immigrants allowed into the country. Understanding the process through which assimilation occurs is also crucial for determining how best to aid their adjustment upon arrival. Although there is a significant body of literature on the economic assimilation of immigrants, surprisingly little research has been done on what could be both a major catalyst for and result of the process: the social integration of immigrants. ${ }^{1}$ This paper examines social integration by using interethnic marriage as its measure.

Many empirical papers have found positive relationships between intermarriage and other aspects of assimilation. Meng and Gregory (2005) find that even after controlling for standard measures of human capital, intermarried immigrants in Australia have 15-23 percent higher earnings than non-intermarried immigrants. ${ }^{2}$ They explain that this may be due to the critical role of social networks in the job search process. Marrying a native certainly increases the proportion of natives in one's social circle, and since natives typically have lower unemployment rates and higher wages, forming relationships with them may have a positive effect on immigrants' labor market outcomes.

Intermarriage plays an even greater role in the assimilation of the children of immigrants. Children with intermarried parents complete more years of schooling than do children with two immigrant parents (Chiswick and DebBurman 2004). Compared to children of two foreign-born

\footnotetext{
${ }^{1}$ Borjas (1995), Edin et al. (2003), and Munshi (2003) all find evidence of the importance of social contacts in the economic assimilation of immigrants.

${ }^{2}$ Caution should be used in interepreting this result since Kantarevic (2004) finds that after accounting for the positive selection into interethnic marriages, the intermarriage premium disappears.
} 
parents, the odds of dropping out of high school are 27 percent lower for children with a nativeborn father and 22 percent lower for children with a native-born mother (Ramakrishnan 2004). Correspondingly, those second-generation immigrants with a native-born parent have lower average earnings than those with two immigrant parents (Ramakrishnan 2004). Children of intermarried immigrants are also more likely to marry outside of their ethnic group (Cohen 1977), potentially further reinforcing the positive effects of intermarriage on other dimensions of assimilation through the generations.

Because schooling levels can be directly affected by public policy, it is particularly important to understand how human capital affects the probability of intermarriage. Moreover, as suggested by Duncan and Trejo (2005), if education is positively related to intermarriage and children of intermarried parents are less likely to associate with any specific ethnicity, then estimates of intergenerational assimilation as measured by education outcomes may be biased downward. ${ }^{3}$ This paper examines the mechanisms through which education affects intermarriage decisions.

Previous empirical studies of the relationship between education and intermarriage have produced mixed results. A number of authors have found a positive relationship (e.g. Meng and Gregory 2005, Lichter and Qian 2001, Cohen 1977). However, Hwang, Saenz, and Aguirre (1996) find that Asian women with lower levels of education are more likely to outmarry racially. Kitano et al. (1984) find no relationship between occupational status and outmarriage for Chinese, Japanese, and Koreans in California. Based on another set of studies, Lieberson and Waters (1988) conclude that the influence of education on ethnic endogamy, marriage within ethnicity, is relatively small. In this paper, I develop a model that can reconcile all of these seemingly contradictory findings.

In line with the explanations for the scarcity of interracial marriages presented by Wong (2003), I argue that the mechanisms through which human capital affects ethnic endogamy fall into three

\footnotetext{
${ }^{3}$ Duncan and Trejo (2005) find evidence of this for the case of Mexican Americans.
} 
main categories. ${ }^{4}$ First, education may improve immigrants' abilities to adapt to the customs and culture of the host country. For example, educated immigrants may be more fluent in the host country's language, and so they can share a household with a native more efficiently. I call this explanation of the negative relationship between education and endogamy the cultural adaptability effect.

Another way in which education may decrease the likelihood of endogamy is through its effect on migration patterns. For example, by increasing the geographic scope of the labor market, education may result in outmigration from ethnic enclaves. Leaving areas with high foreign-born concentrations makes it more difficult to meet potential spouses of the same ethnicity and so, even if preferences remain constant, the probability of intramarriage decreases. I call this the enclave effect.

Lastly, it has been widely shown in both the theoretical and empirical marriage literature that there is assortative matching on education in the marriage market. This implies that even if people do not care at all for marrying within ethnicity, there could be high endogamy rates if the distributions of education vary by ethnicity. In the more likely scenario that immigrants care both about a spouse's ethnicity and education level, because search is costly, they may be willing to trade similarities in ethnicity for similarities in education. Regardless of whether immigrants have preferences for marrying within their ethnicity, the assortative matching effect implies that an increase in education should result in a decrease in endogamy for people in low education ethnic groups but an increase in endogamy for people in high education ethnic groups.

In this paper, I first derive an identification strategy for differentiating the cultural adaptability effect from the assortative matching effect. I then obtain empirical estimates of their relative

\footnotetext{
${ }^{4}$ Wong's three explanations for the lack of interracial marriages are a mating taboo, scarcity of courting opportunities, and differences in individual endowments between blacks and whites. By structurally estimating the impact of these three explanations, she finds that eliminating the mating taboo would be the only successful way to increase interracial marriages (Wong 2003).
} 
importance while controlling for the enclave effect. I find that assortative matching on education is the most important avenue through which human capital affects the probability of intermarriage.

The empirical analysis is conducted solely on second-generation immigrants, the native born children of immigrants. Their marriage decisions are studied because they are less likely to suffer from language barriers and more likely to be exposed to the U.S. marriage market. Beyond these practical concerns, second-generation immigrants are an interesting demographic group in themselves since, although they are born and most likely raised in the U.S., they continue to exhibit marked preferences toward spouses of their ethnicity. ${ }^{5}$

The structure of this paper is as follows. In Section 2, I present a theoretical model of the interethnic marriage decision which provides an identification strategy for disentangling the different mechanisms through which human capital affects interethnic marriage decisions. A description of the sample used, descriptive statistics, the empirical specification of the test implied by the model, and empirical results are discussed in Section 3. In order to provide further support for the model, I present and test two of its additional implications in Section 4 . Section 5 concludes.

\section{A Theoretical Model of Spouse-Search}

Many sociologists and a few economists have produced descriptive papers detailing the extent and possible reasons for intermarriage, but very few have attempted to formally model immigrants' decisions of whom to marry. ${ }^{6}$ In this section, a theoretical framework of interethnic marriage decisions is presented and then used to specifically analyze the effect of education on these decisions.

Starting with the pioneering work of Becker (1981), economists and sociologists have used

\footnotetext{
${ }^{5}$ Angrist (2002) exploits the high endogamy rates of second-generation immigrants to test for the importance of sex ratios on various economic and demographic outcomes.

${ }^{6}$ The only exception that I am aware of is Bisin and Verdier (2000). Bisin, Topa, and Verdier (2004) structurally estimate a model of interreligious, as opposed to interethnic, marriages. Wong (2003) structurally models interracial marriages, but does not specifically study intermarriages among immigrants.
} 
economic theory to analyze who marries whom. By assuming efficiency in the marriage market, Becker predicts positive assortative matching of spouses on any quantitative trait for which the marginal productivity of the husband's trait on household production depends positively on the wife's trait. He cites intelligence, education, health, fecundity, religion, and ethnic origin as examples of traits for which this is likely to be the case. Lam (1988) extends Becker's analysis to allow for gains from marriage due to the joint consumption, as opposed to production, of household public goods. The model presented below builds on these models but also incorporates the fact that because of search frictions and uncertainties, optimal matches do not always occur.

Figure 1 provides a game tree representation of the spouse-search process. For simplicity, the process is set up as a one-sided game in which the man proposes marriage to a woman if it is in his best interest and the woman always accepts the marriage proposal. ${ }^{7}$ I assume that there are only two relevant types of women: Ethnics (women of the man's ethnicity) and Americans (women of a different ethnicity). Each man lives for two periods. In the first period, the man randomly meets an Ethnic with probability $p$ and an American with probability $1-p$. One can think of these probabilities as the proportion of the population within close geographic proximity that is of his own ethnicity. The woman he meets has a level of education, $h^{w}$, drawn from the distribution $F_{e}$ if she is Ethnic and $F_{a}$ if she is American. Let $h_{e}^{w}$ denote a draw of education from the Ethnic distribution and $h_{a}^{w}$ denote a draw of education from the American distribution. After observing the ethnicity and level of education of the woman with whom he is matched in the first period, the man decides whether to marry her or remain single until the second period. In the second period, the game is repeated but then he must choose either to marry the woman he is matched with or remain single for the remainder of his life. For simplicity, I will assume that everyone prefers marriage to anyone above being a life-long bachelor. Thus, the only decision made in this

\footnotetext{
${ }^{7}$ Of course, the symmetric case where women make proposals and men always accept would imply symmetric results. An extension of the model to the case where women can reject proposals is discussed later in the paper.
} 


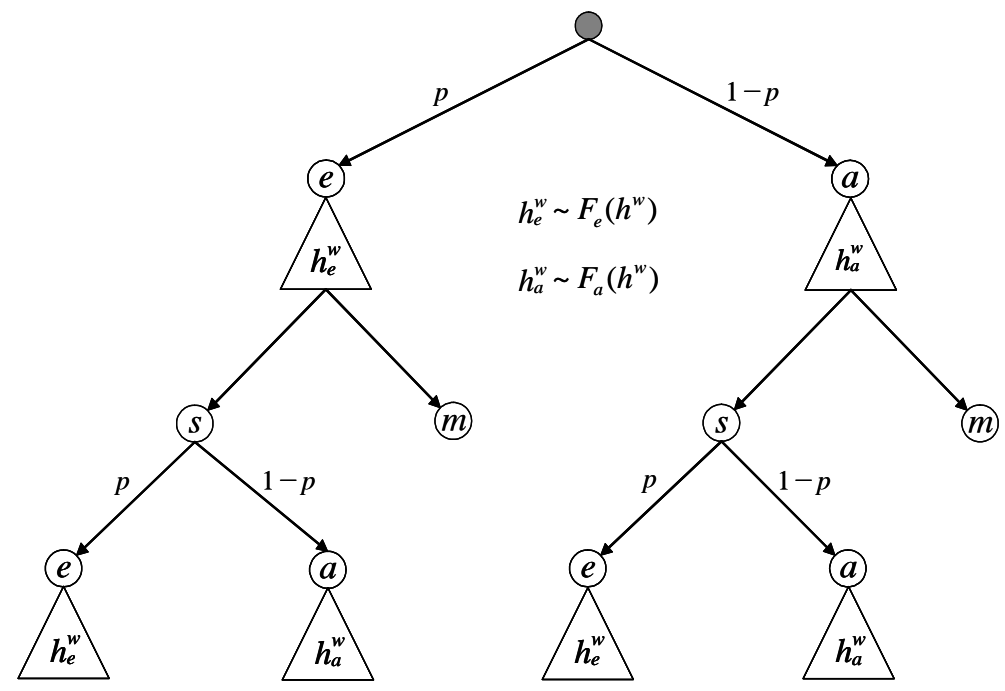

Figure 1: A Model of Spouse-Search

game is whether or not to marry in the first period. The man will choose to marry in the first period if his utility from the first period match is greater than his expected utility in the second period. I assume that although he does not know exactly with whom he will be matched in the second period, he does know the distributions of education in both populations and the probability of getting a draw from each population.

There are two important components to husband $i$ 's utility from marriage: his preferences for marrying within his ethnicity and within a similar education level. Because returns from marriage can result at least partially from the joint consumption of household public goods (Lam 1988), it is optimal for couples to sort in the marriage market according to their similar demands for these goods. Because so many goods jointly consumed in the household are related to ethnicity, it is efficient for immigrants to marry someone of the same ethnicity. Language, cuisine, holiday celebrations, and other family traditions are some examples of household public goods related to ethnicity. There is evidence that interethnic marriages are more likely to end in divorce (Kalmijn et al. 2005). These divorces could be a result of a failure to agree on important ethnicity-specific 
household public goods. Preferences for household public goods can also be related to people's education levels. For example, education is related to liberal sex-role attitudes (Davis 1982), a desire for fewer children (Kohn 1977), preferences over how to spend leisure time together (Robinson 1977), and political views (Hyman and Wright 1977). Because children, joint vacations, and political conversations can all be considered household public goods, it is also efficient for couples to sort in the marriage market according to their demands for these public goods and, consequently, to sort by education level. Using synthetic cohorts from the 1960 U.S. Census, Kalmijn (1993) finds that educational homogamy among second-generation immigrants has increased while ethnic endogamy has decreased.

Because people prefer to marry within both their ethnic and education groups, but spouse search is costly, individuals may trade similarities in ethnicity for similarities in education. Preferences for similarities in education are modeled using a simple quadratic loss function composed of the difference between spousal education levels. The ethnicity of the spouse enters into the utility function as an additively separable term, $T\left(h_{i}, X_{i}\right)$ where $h_{i}$ is the man's level of education and $X_{i}$ is a vector of all characteristics other than education that determine a man's taste for marrying an Ethnic. This term is normalized to zero in the utility from marrying an American. Thus, the utility of an Ethnic man $i$ from marrying an Ethnic and an American respectively can be written,

$$
\begin{aligned}
U_{i e} & =T\left(h_{i}, X_{i}\right)-\left(h_{e}^{w}-h_{i}\right)^{2} \\
U_{i a} & =-\left(h_{a}^{w}-h_{i}\right)^{2}
\end{aligned}
$$

For simplicity, let $T\left(h_{i}, X_{i}\right)=a\left(X_{i}\right)-b h_{i}$ where $b$ is a parameter measuring the effect of the man's education on his taste for marrying within ethnicity. If tastes for ethnicity are non-negative, then 
$a\left(X_{i}\right) \geq b h_{i} . \quad$ According to the cultural adaptability hypothesis, educated individuals are better able to learn the customs associated with the native culture, and so they do not care as much for ethnicity-specific household public goods. That is, immigrants with high levels of education may not consider ethnicity such an important characteristic in a spouse. If the cultural adaptability hypothesis is true, $T\left(h_{i}, X_{i}\right)$ depends negatively on education and thus $b>0$. Characteristics in the $X$ vector could include, for example, personal ethnic identity, traditionality, religion, country of origin, age at marriage, and age.

The only decision made in this game is whether or not to marry in the first period. The man will marry in the first period if the utility he gets from marriage exceeds his expected utility in the second period. Supresssing subscripts, his expected utility from waiting, i.e. his reservation utility, can be written,

$$
\begin{aligned}
R & =p E\left[U_{e}\right]+(1-p) E\left[U_{a}\right]-\tau \\
& =p\left(T\left(h_{i}, X_{i}\right)-E\left[\left(h_{e}^{w}-h_{i}\right)^{2}\right]\right)+(1-p)\left(-E\left[\left(h_{a}^{w}-h_{i}\right)^{2}\right]\right)-\tau
\end{aligned}
$$

where $\tau>0$ reflects the utility cost of delaying marriage due to intertemporal preferences. Note that the probability of being matched with someone of the same ethnicity remains the same in both periods. To start, the variances in education for the two populations will be assumed equal, but deviations from this assumption are discussed in Section 4.

The probability of marrying in the first period given that he is matched with a woman of his own ethnicity is equal to the probability that the utility from that woman is greater than his reservation utility. This is,

$$
\operatorname{Pr}\left(U_{e}>R\right)=\operatorname{Pr}\left(T-\left(h_{e}^{w}-h_{i}\right)^{2}>R\right)
$$




$$
\begin{aligned}
& =\operatorname{Pr}\left(h-\sqrt{T-R}<h_{e}^{w}<h+\sqrt{T-R}\right) \\
& =F_{e}(h+\sqrt{T-R})-F_{e}(h-\sqrt{T-R}) \text { assuming } h_{e}^{w} \text { continuous } \\
& \equiv F_{e}\left(L_{e}^{u}\right)-F_{e}\left(L_{e}^{l}\right)
\end{aligned}
$$

Similarly, if he is matched with an American,

$$
\begin{aligned}
\operatorname{Pr}\left(U_{a}\right. & >R)=\operatorname{Pr}\left(-\left(h_{a}^{w}-h_{i}\right)^{2}>R\right) \\
& =\operatorname{Pr}\left(h-\sqrt{-R}<h_{a}^{w}<h+\sqrt{-R}\right) \\
& =F_{a}(h+\sqrt{-R})-F_{a}(h-\sqrt{-R}) \text { assuming } h_{a}^{w} \text { continuous } \\
& \equiv F_{a}\left(L_{a}^{u}\right)-F_{a}\left(L_{a}^{l}\right)
\end{aligned}
$$

Intuitively, $L_{e}^{u}$ and $L_{e}^{l}$ denote the upper and lower limits of acceptable levels of education for Ethnics while $L_{a}^{u}$ and $L_{a}^{l}$ denote limits for Americans. Note that because people have a preference for marrying within their ethnicity, $T>0$, the range of education levels acceptable for Ethnics is wider than the range acceptable for Americans.

If the game were altered so that spouse-searchers could choose to remain single after viewing their second period match, the bands of acceptable matches in the first period would become narrower, but this would not change any of the central implications of the model. Moreover, since only around 5 percent of the population never marry in their lifetime, this is not a serious flaw to the model (U.S. Census Bureau 2002).

There are three ways in which a man can end up married to a woman of his own ethnicity by the end of the game. First, he can be randomly matched with an Ethnic (with probability $p$ ) in the first period and choose to marry her. Second, he can first be matched with an Ethnic, choose not to marry her, but be randomly matched with another Ethnic in the second period. Third, 
he can be matched with an American in the first period, decide not to marry her and be matched with a woman of his own ethnicity in the second period. Thus, the probability of endogamy can be written with three components ${ }^{8}$ :

$$
\begin{aligned}
\operatorname{Pr}(\text { Endogamy })= & p \operatorname{Pr}\left(U_{e}>R\right)+p\left(1-\operatorname{Pr}\left(U_{e}>R\right)\right) p+ \\
& (1-p) \operatorname{Pr}\left(1-\operatorname{Pr}\left(U_{a}>R\right)\right) p
\end{aligned}
$$

Inserting equations (4) and (5) into (6) and then rearranging terms, a more intuitive expression can be written,

$$
\operatorname{Pr}(\text { Endogamy })=p+p(1-p)\left\{\left[F_{e}\left(L_{e}^{u}\right)-F_{e}\left(L_{e}^{l}\right)\right]-\left[F_{a}\left(L_{a}^{u}\right)-F_{a}\left(L_{a}^{l}\right)\right]\right\}
$$

The first term in equation (7) represents the random matching component of the spouse search process while the second term represents the component arising from preferences. Naturally, the higher the probability of encountering an Ethnic, the higher the probability of marrying one. Moreover, if $p=0$, the probability of endogamy is zero while if $p=1$ the probability of endogamy is one. Figure 2 helps to understand the preference aspect of the model. The diagram depicts probability density functions for education levels of Ethnics and Americans. In this example, Ethnics are assumed to have lower levels of education than Americans. Recall that all Ethnics with education levels between $L_{e}^{u}$ and $L_{e}^{l}$ will be accepted while only Americans with education levels between $L_{a}^{u}$ and $L_{a}^{l}$ will be accepted. Thus, the difference between the area under the Ethnic distribution between $L_{e}^{u}$ and $L_{e}^{l}$ and the area under the American distribution between $L_{a}^{u}$ and $L_{a}^{l}$

\footnotetext{
${ }^{8}$ The model can fairly easily be extended to a two-sided framework by incorporating a potential spouse's ability to reject a marriage proposal in the first period. Intuitively, the biggest change to the model is that it becomes more likely that people will be randomly matched in the second period (a smaller weight is given in the final expression to preferences). The qualitative implications of the model do not change.
} 
represents the component of endogamy arising from preferences, unweighted by $p(1-p)$. In this example, because education of the man is very low and Ethnics have lower levels of education, the endogamy rate is greater than what is implied by random matching. The area under the Ethnic distribution between the outer acceptance limits and the inner acceptance limits represents tastes for ethnicity unrelated to people's preferences for similarities in education levels.

\subsection{Cultural Adaptability}

According to the cultural adaptability effect, an increase in education decreases a person's tastes for marrying within ethnicity because he or she can more easily assimilate to the host country. This implies that regardless of a person's ethnicity, an increase in education leads to a decrease in endogamy.

Proposition 1 According to teh cultural adaptability hypothesis, the effect of an increase in education on endogamy is never positive.

Proof: In order to look at the effect of education on endogamy solely through tastes, we need only take the derivative of equation (7) with respect to $T$ and then take the derivative of $T$ with respect to $h$. Thus,

$$
\begin{aligned}
\frac{\partial \operatorname{Pr}(\text { Endogamy })}{\partial T}= & \frac{1}{2} p(1-p)^{2}(T-R)^{-\frac{1}{2}}\left[f_{e}\left(L_{e}^{u}\right)+f_{e}\left(L_{e}^{l}\right)\right]+ \\
& \frac{1}{2} p^{2}(1-p)(-R)^{-\frac{1}{2}}\left[f_{a}\left(L_{a}^{u}\right)+f_{e}\left(L_{a}^{l}\right)\right] \\
> & 0
\end{aligned}
$$

Since $\frac{\partial T}{\partial h}=-b$ and, if the cultural adaptability hypothesis is true, $b>0$, by the chain rule, the effect of education through cultural adaptability is always negative regardless of $h, p$, or even whether one belongs to a high education ethnicity or a low education ethnicity. 


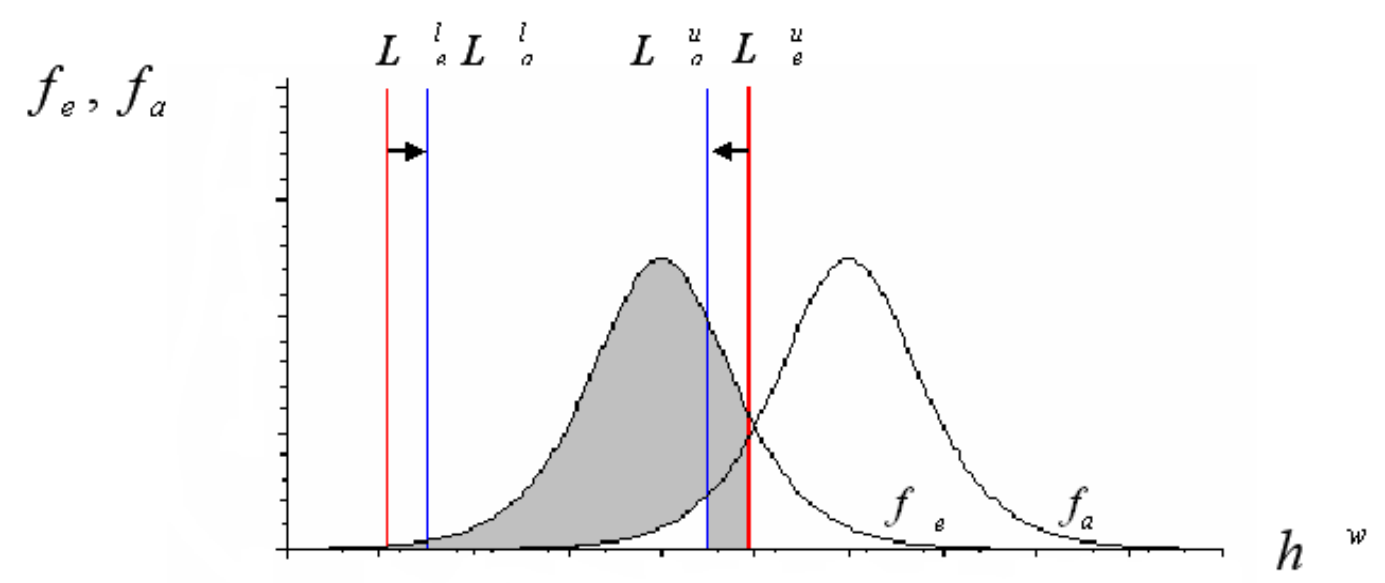

Figure 2: Cultural Adaptability Effect of Education

As education increases, $T$ approaches zero since, by assumption, zero is the minimum value of T. As $T$ approaches zero, the acceptable values of education for Ethnics move closer and closer to the limits for Americans as depicted by the arrows in Figure 2. Thus, the shaded region in the figure necessarily decreases regardless of the distributions of education in the two populations and the man's level of education. This finding lets us identify the cultural adaptability effect in the data.

\subsection{Assortative Matching}

In order to clearly differentiate the assortative matching effect from the cultural adaptability effect, I will assume that immigrants have no taste for marrying within ethnicity, $T=0$, and care only about marrying someone with a similar level of education. This assumption has two consequences. First, as can be seen from equation (3), the reservation utility increases by the size of the tastes weighted by the probability of being matched with an Ethnic, $p T$. More importantly, however, when $T=0$, the range of acceptable levels of education in the first period is the same for Ethnics and Americans: $L_{e}^{u}=L_{a}^{u}$ and $L_{e}^{l}=L_{a}^{l}$. I let $L^{u}$ denote the common upper limit of the acceptance region and $L^{l}$ denote the common lower limit. The probability of marrying within ethnicity can 


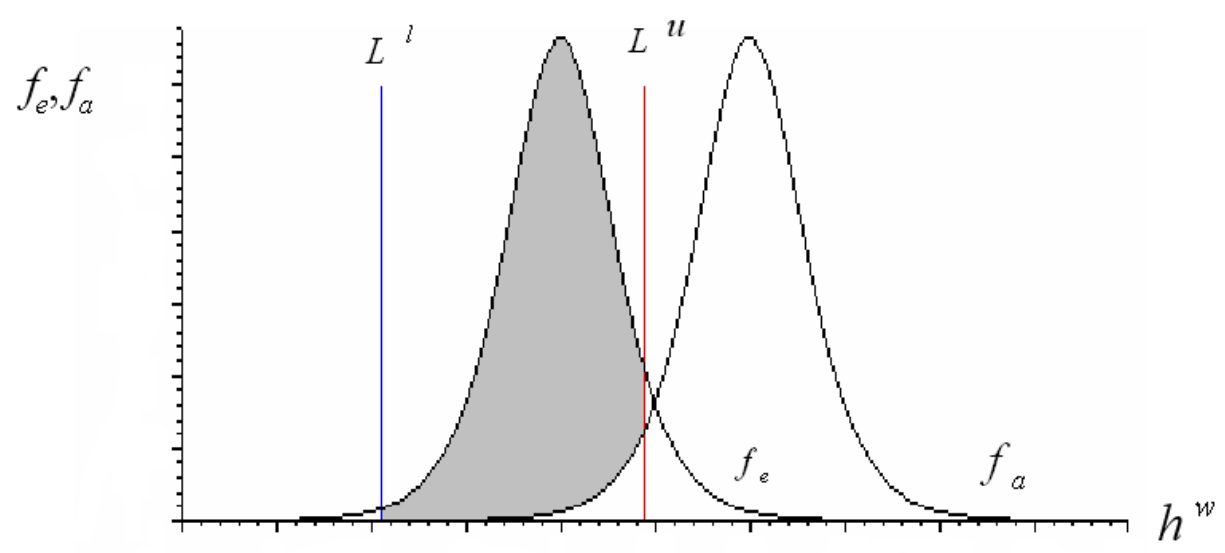

Figure 3: Probabilty of Endogamy when $\mathrm{T}=0$

then be written

$$
\operatorname{Pr}(\text { Endogamy })=p+p(1-p)\left\{\left[F_{e}\left(L^{u}\right)-F_{e}\left(L^{l}\right)\right]-\left[F_{a}\left(L^{u}\right)-F_{a}\left(L^{l}\right)\right]\right\}
$$

Figure 3 depicts the preference portion of the probability of marrying within ethnicity for a person with a low level of education. The shaded region shows the probability of marrying within ethnicity above that which is implied by random matching. Notice that even with no preference for marrying within ethnicity, assortative matching on education can yield high endogamy rates if education distributions differ by ethnicity. As education increases, however, the acceptable limits shift rightward as shown by the arrows in Figure 4 to levels of education that are more frequent among Americans than Ethnics. Of course, when Americans typically have less education than Ethnics, the acceptance limits shift toward education levels that are more frequent among Ethnics. Formally, the derivative of equation (8) with respect to the man's education is

$$
\begin{aligned}
\frac{d \operatorname{Pr}(\text { Endogamy })}{d h}= & p(1-p)\left(1-\frac{d R / d h}{2 \sqrt{-R}}\right)\left[f_{e}\left(L^{u}\right)-f_{a}\left(L^{u}\right)\right]- \\
& p(1-p)\left(1+\frac{d R / d h}{2 \sqrt{-R}}\right)\left[f_{e}\left(L^{l}\right)-f_{a}\left(L^{l}\right)\right]
\end{aligned}
$$


The first component of equation (9) represents the change in endogamy due to the shift of the upper limit and the second component represents the change due the shift of the lower limit. More specifically, $1-\frac{d R / d h}{2 \sqrt{-R}}$ represents the amount by which the right hand side of the acceptance region shifts with an increase in the man's education while $1+\frac{d R / d h}{2 \sqrt{-R}}$ represents the shift in the left hand side of the acceptance region. Because of the quadratic loss resulting from differences in education levels between spouses, an increase in education of the man shifts the acceptance region (both the left and right hand side limits) to the right.

Proposition 2 An increase in the man's education results in a shift to the right of the accepted values of education of possible wives.

$$
1-\frac{d R / d h}{2 \sqrt{-R}}>0 \text { and } 1+\frac{d R / d h}{2 \sqrt{-R}}>0
$$

\section{Proof: See Appendix A.}

The effect of an increase in education on endogamy is illustrated in Figure 4. The darker shaded region represents the increase in endogamy resulting from the rightward shift of the right-hand limit while the lightly shaded region represents the decrease in endogamy resulting from the rightward shift of the left-hand limit. For the example depicted in the diagram, since the darker shaded region is smaller than the lightly shaded region, the increase in education will result in a decrease in endogamy. If the labels on the two distributions were reversed, as would be the case for an immigrant in a high education ethnicity, then an increase in education would result in an increase in endogamy. Thus, a very intuitive implication arises from the assortative matching theory: an increase in education will lead to a decrease in endogamy for people in low education ethnicities and an increase for people in high education ethnicities. In actuality, however, the model requires a few additional conditions in order to predict this result. 


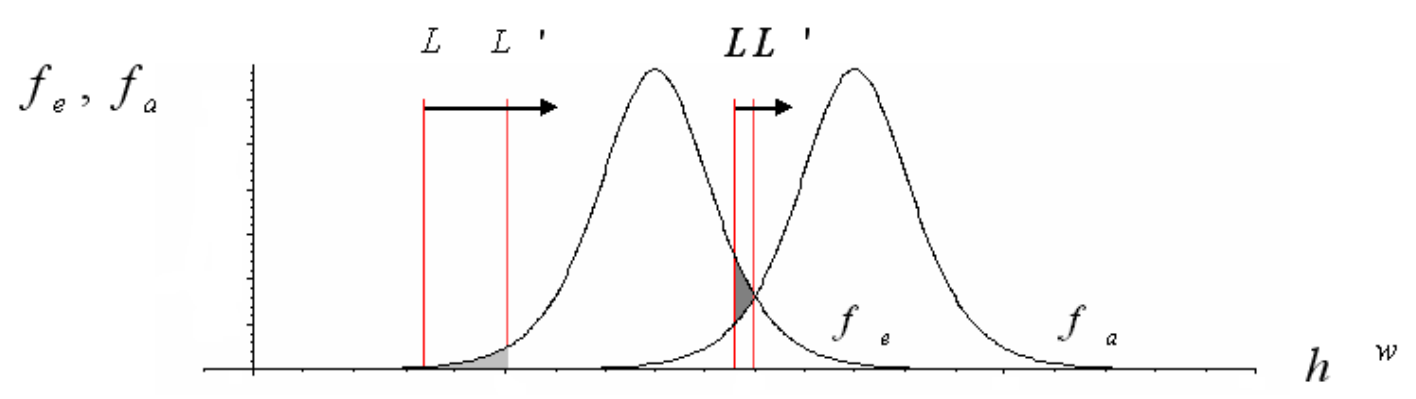

Figure 4: Assortative Matching Effect of Education on Endogamy

Proposition 3 Assuming $f_{e}$ and $f_{a}$ are two continuous and identical distributions with different means but the same variance, $T=0$, and $\bar{h}_{e}^{w}<\bar{h}_{a}^{w}$, then there exists an $h^{*}\left(p, \sigma^{2}, \bar{h}_{a}^{w}, \bar{h}_{e}^{w}\right)$ such that if either $p>1 / 2$ and $h>h^{*}, p<1 / 2$ and $h<h^{*}$, or if $p=1 / 2$, an increase in $h$ will yield a decrease in the probability of marrying within ethnicity.

$$
\frac{d \operatorname{Pr}(\text { Endogamy })}{d h}<0 \text { if } \bar{h}_{e}^{w}<\bar{h}_{a}^{w}
$$

If $\bar{h}_{e}^{w}>\bar{h}_{a}^{w}$, the opposite is true. That is, if either $p<1 / 2$ and $h>h^{*}, p>1 / 2$ and $h<h^{*}$, or if $p=1 / 2$, then an increase in $h$ will yield an increase in the probability of marrying within ethnicity.

$$
\frac{d \operatorname{Pr}(\text { Endogamy })}{d h}>0 \text { if } \bar{h}_{e}^{w}>\bar{h}_{a}^{w}
$$

Proof: See Appendix B.

For expositional purposes, I will defer a discussion of these conditions until Section 4. For now, it is enough to point that these conditions hold in general.

To summarize the implications of the model presented thus far, an increase in education always leads to a decrease in the probability of marrying within ethnicity through the cultural adaptability effect, but has differential implications through the assortative matching effect. The enclave effect 
is not directly modeled in that $p$ is not written as a function of $h$. However, the enclave effect is accounted for in the empirical section of this paper when differentiating the cultural adaptability from the assortative matching effect.

\section{The Data}

\subsection{Sample}

This study uses the 1970 Form 2 PUMS metro sample in conjunction with the 1970 Fourth Count Population Summary Tape Files, SF 4. I study specifically the marriage decisions of secondgeneration immigrants because they are less likely to suffer from language barriers, and their exposure to U.S. marriage markets is clearer. Also, since a principle way immigrants can become U.S. citizens is through marriage to a native, marriage choices may depend a great deal on the type of visa immigrants hold (Jasso and Rosenzweig 1990, Jasso et al. 2000). By examining just the decisions of second-generation immigrants, who are by birth citizens of the U.S., motives behind interethnic marriages are clearer. This specific sample is used because Form 2 in census year 1970 was the last time census respondents were asked for their parents' country of birth. ${ }^{9}$ I will only consider marriage decisions of native-born children with two foreign-born parents. Since the PUMS only reports the father's country of birth if both parents are foreign born, the ethnicity of second-generation immigrants is determined by the father's birthplace. Since, according to the 2000 Current Population Survey, 98.5 percent of all children with two immigrant parents are children of immigrant parents from the same country, I do not think this limitation influences the central results.

Because the 1970 PUMS is only a one percent sample of the U.S. population, it is very difficult

\footnotetext{
${ }^{9}$ Since 1970 , a question on ancestry has been asked, but there is no way to know how many generations families have been in the U.S. It is also unclear what causes people to differentially associate with various ethnic backgrounds.
} 
to obtain accurate measures of the size of the ethnic group within close geographic proximity. The SF 4 contains 15 percent sample data inflated to represent the total U.S. population. Population items used in this analysis are counts of the foreign born and native born (of foreign or mixed parentage) constructed for each ethnicity at various geographic summarization levels. I am able to match the PUMS with the Summary Files by country, state, and county group subarea. ${ }^{10}$ County groups are made up of an urban center and surrounding counties where economic activity is focused at the center. Since the central urban area is considered to be the labor market center, it is not unreasonable to believe that it is also the marriage market center. Many large county groups are divided into two or more subareas. These identify metropolitan areas or county components of metropolitan areas with more than 250,000 residents. In my sample, there are approximately 280 county group subareas. There are over 2 million individual observations in the PUMS and over 400 thousand married couples where the spouse is present in the household. The analysis presented in this paper is performed on the 39,943 married second-generation male immigrants within ethnicities with over 1000 observations in the sample. I have completed the same analysis on second-generation females and results are qualitatively the same.

\subsection{Variables}

A second-generation male is considered to be ethnically intramarried in this analysis if his wife has at least one parent born in the country of birth of his father. Note that by this definition, a second-generation male will be considered ethnically intramarried if he marries an immigrant, a woman whose parents were both born abroad, or a woman with one parent born abroad, as long as the couple shares a common ethnicity. In more technical terms, $y$, the endogamy dummy, is equal

\footnotetext{
${ }^{10}$ The finest geographic partition within the PUMS metro sample is the county group. The SF 4 files do not contain population counts for county groups, but do contain them for counties. I simply sum county counts within county group to get the county group information.
} 
to one if the ethnicity of the husband is the same as the ethnicity of his wife and zero otherwise.

In the PUMS, education is measured in levels. In order for the regression coefficients to be more easily interpreted, I construct the years of schooling variable by mapping these levels into the average number of years it takes for people to complete them according to Chiswick and DebBurman (2004). A dummy variable for whether or not English is a person's native language, is used as a proxy for ethnic identity which is in the $X$ vector in the model. Parents choose the mother tongue of their children. Children of parents with strong ethnic attachments are more likely to have a non-English mother tongue and identify with their parents' country of birth (Stevens 1987). The Non-English Native Tongue variable takes on the value one if English is not the native tongue and zero if it is. Age is another variable in the $X$ vector. Since children have gained more independence from parents as society has modernized in the past century (Kalmijn 1991), parental preference for the intramarriage of their children may be less of a salient factor in ethnic preferences of younger second-generation immigrants. The variable, Ethnic Group Size, is used as a proxy for the probability of meeting someone of the same ethnicity, $p$. It is constructed using the summary data file by dividing the number of people of that ethnicity (immigrant or native born with at least one parent born abroad) by the number of people in the population. When regressions are run for smaller geographic partitions than the entire country, average levels of education are also specific to the person's residence. For example, average education in ethnicity in the person's county group is used for the county group level regressions.

\subsection{Descriptive Statistics}

Table 1 presents the distribution of types of spouses for second-generation male immigrants between the ages of 16 and 65. Note that even though Americans (3rd generation or above immigrants) make up around 85 percent of the population, only about half of second-generation men marry 


\begin{tabular}{lll}
\hline Marriage Type & Number & Percentage \\
\hline \hline Immigrant, Same Ethnicity & 1252 & 3.3 \\
2nd Generation, Same Ethnicity & 8188 & 21.6 \\
American & 19949 & 52.7 \\
Immigrant, Differerent Ethnicity & 2013 & 5.3 \\
2nd Generation, Different Ethnicity & 6250 & 16.5 \\
Immigrant, Parents Same Ethnicity & 189 & 0.5 \\
\hline Total & 37841 & 100 \\
\hline
\end{tabular}

Table 1: Frequencies of Marriage Types for Second-Generation Males

Americans. In fact, one in every four second-generation men marry within their ethnicity. Since second-generation immigrants as a group make up only around 3 percent of the entire population, the fact that 21 percent of second-generation immigrants marry second-generation women of their own ethnicity is something to be noticed.

The prevalence of endogamous marriages becomes even more apparent when comparing actual rates of endogamy with endogamy rates implied by random matching for each ethnicity. As seen in Table 2, for example, since Italians constitute 2.09 percent of the population of the U.S., random matching within the U.S. would imply an endogamy rate of 2.09 percent. The actual endogamy rate of 43 percent is over 20 times this amount. As discussed previously, it may not be reasonable to compare endogamy rates to the rates implied by random matching within the entire country since marriage markets do not extend to the entire country. Since immigrants and their children tend to live in or near ethnic enclaves, it makes more sense to look at the ethnic population proportions within states and county groups. The average Italian lives in a county group in which Italians make up 5 percent of the population. This still is not even close to the endogamy rate of 43 percent. Even in the county group with the largest proportion of foreign stock of any particular ethnicity, Mexicans make up 40 percent of the population in that county group. As expected, the random matching rate of 40 percent within the county group is closer to the actual endogamy rate of 53 but it remains lower. Table 2 also presents ethnicity specific statistics on education levels. Notice that there are significant differences in average number of years of education among ethnicities. Average years of education ranges from a little over 8 years for Mexicans to over 12 


\begin{tabular}{|c|c|c|c|c|c|}
\hline Ethnicity & Endogamy Rate & $\begin{array}{l}\text { Percentage of } \\
\text { Population in } \\
\text { Ethnicity }\end{array}$ & $\begin{array}{c}\text { Average } \\
\text { Percentage of } \\
\text { Population in } \\
\text { Ethnicity in County } \\
\text { Group }\end{array}$ & $\begin{array}{l}\text { Mean Years of } \\
\text { Schooling }\end{array}$ & $\begin{array}{l}\text { Standard } \\
\text { Deviation }\end{array}$ \\
\hline Canada & $\overline{c 17.24}$ & 1.49 & "4.55 & 111.04 & 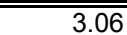 \\
\hline Mexico & 53.61 & 1.15 & 6.42 & 8.35 & 3.98 \\
\hline Sweden & 10.05 & 0.40 & 0.95 & 11.51 & 2.73 \\
\hline Ireland & 13.53 & 0.71 & 1.58 & 11.91 & 2.79 \\
\hline Italy & 42.92 & 2.09 & 5.10 & 10.43 & 2.85 \\
\hline Austria & 12.65 & 0.48 & 0.81 & 11.03 & 3.04 \\
\hline Czechoslovakia & 17.54 & 0.37 & 0.85 & 10.53 & 2.80 \\
\hline Germany & 10.41 & 1.78 & 2.39 & 11.02 & 3.03 \\
\hline Hungary & 11.58 & 0.30 & 0.56 & 10.94 & 2.87 \\
\hline Poland & 31.75 & 1.17 & 2.44 & 10.56 & 3.05 \\
\hline Yugoslavia & 19.98 & 0.22 & 0.53 & 10.87 & 2.77 \\
\hline Lithuania & 20.02 & 0.16 & 0.33 & 11.07 & 3.03 \\
\hline Russia & 34.75 & 0.96 & 2.22 & 12.29 & 3.10 \\
\hline
\end{tabular}

Table 2: Descriptive Statistics by Ethnicity

\begin{tabular}{|c|c|c|c|c|c|}
\hline \multirow[b]{3}{*}{$\begin{array}{l}\text { Years of } \\
\text { Schooling }\end{array}$} & \multirow[b]{3}{*}{$\begin{array}{c}\text { Number } \\
\text { Married } \\
\text { Males }\end{array}$} & \multirow[b]{3}{*}{$\begin{array}{l}\text { Education } \\
\text { Distribution } \\
\text { of Females }\end{array}$} & \multirow[b]{3}{*}{$\begin{array}{c}\text { Actual } \\
\text { Endogamy }\end{array}$} & \multicolumn{2}{|c|}{ Implied Endogamy Rates } \\
\hline & & & & $\begin{array}{c}1970 \text { Census, } \\
\text { SF } 4 \\
\end{array}$ & 1970 PUMS \\
\hline & & & & $\begin{array}{l}\text { Mean County } \\
\text { Group }\end{array}$ & $\begin{array}{c}\text { Mean } \\
\text { Neighborhood }\end{array}$ \\
\hline Mexicans & & & & $p=.07$ & $p=.181$ \\
\hline$\overline{0-4}$ & 15 & 0.24 & 0.72 & 0.44 & 0.67 \\
\hline $4-6$ & 193 & 0.30 & 0.65 & 0.16 & 0.34 \\
\hline $6-8$ & 252 & 0.13 & 0.63 & 0.08 & 0.18 \\
\hline $8-10$ & 764 & 0.25 & 0.50 & 0.04 & 0.10 \\
\hline $10-12$ & 228 & 0.05 & 0.36 & 0.03 & 0.08 \\
\hline $12-14$ & 266 & 0.02 & 0.47 & 0.02 & 0.05 \\
\hline 14-16 & 205 & 0.01 & 0.26 & 0.02 & 0.05 \\
\hline Russians & & & & $\mathrm{p}=.024$ & 0.078 \\
\hline $0-4$ & 25 & 0.03 & 0.16 & 0.03 & 0.08 \\
\hline 4-6 & 390 & 0.14 & 0.35 & 0.03 & 0.08 \\
\hline $6-8$ & 407 & 0.09 & 0.29 & 0.02 & 0.05 \\
\hline $8-10$ & 1312 & 0.47 & 0.42 & 0.02 & 0.08 \\
\hline $10-12$ & 493 & 0.12 & 0.38 & 0.02 & 0.08 \\
\hline $12-14$ & 661 & 0.09 & 0.38 & 0.03 & 0.08 \\
\hline $14-16$ & 760 & 0.06 & 0.34 & 0.05 & 0.15 \\
\hline
\end{tabular}

Table 3: Evidence of Preferences for Ethnicity

years for Russians. Standard deviations are around three for all ethnicities.

Because of the substantial amount of dispersion in education levels across ethnicities, assortative matching on education implies that the distributions of education must be considered in order to get a sense for tastes for endogamy. For example, if there are only two ethnicities in a location and members of one ethnicity typically have lower levels of education than the other, then even if there are no preferences for ethnicity, there will be high endogamy rates simply due to assortative 
matching on education. In Table 3, implied endogamy rates for Mexicans, the least educated ethnicity, and Russians, the most educated, are constructed by assuming that people randomly match within education group in close geographic proximity. Due to the limited sample size, I assume that within ethnicity, education distributions do not differ by geography. Since I know the education distributions for Mexicans and Russians as well as Americans, I can calculate implied endogamy rates for different measures of the relevant size of the ethnic group with a straightforward application of Bayes rule. ${ }^{11}$ As expected, the actual endogamy rates presented in column 4 of Table 3 tend to decrease as education increases for Mexicans and increase slightly for Russians. Implied endogamy rates shown in columns 5-6 mirror these patterns for two different estimates of the relevant size of the ethnic group.

In column 5, implied endogamy rates are calculated using the mean proportion of Mexicans living in each county group. Column 6 reports implied endogamy rates using Borjas' estimate of the mean proportion of Mexicans living in the neighborhoods of second-generation Mexicans (Borjas 1995). ${ }^{12}$ For all but the lowest educated group, actual endogamy rates range from being double to ten times as high as implied endogamy rates.

Russians are more educated and less segregated than Mexicans. Implied endogamy rates are highest for Russians with more than 16 years of schooling. Even when using the largest estimate of the relevant size of ethnicity, 7.8 percent, actual endogamy rates are 2 to 4 times as high as implied endogamy rates. To conclude, although assortative matching on education within close

\footnotetext{
${ }^{11}$ To be more specific, the implied endogamy rate is actually the probability of matching with an ethnic given that one must match with someone in the same education group. Thus,

$$
\operatorname{Pr}(\text { Match }=e \mid H=h)=\frac{\operatorname{Pr}(H=h \mid \text { Match }=e) \operatorname{Pr}(\text { Match }=e)}{\operatorname{Pr}(H=h)}
$$

where $\operatorname{Pr}(H=h)=\operatorname{Pr}(H=h \mid M a t c h=e) \operatorname{Pr}(M a t c h=e)+\operatorname{Pr}(H=h \mid M a t c h=a) \operatorname{Pr}(\operatorname{Match}=a)$. The probability that the person is matched with someone of the same ethnicity is $p$ while the probability that the person is matched with someone of a different ethnicity is $1-p$.

${ }^{12}$ Borjas admits that his estimates should be interpreted with caution since the mean number of observations in a neighborhood is 26 and the interquartile range is 9 .
} 


\begin{tabular}{lrrrrrr}
\hline & \multicolumn{2}{c}{ Exogamous Couples } & \multicolumn{2}{c}{ Endogamous Couples } & \multicolumn{2}{c}{ All } \\
\hline & Mean & $\begin{array}{r}\text { Standard } \\
\text { Error }\end{array}$ & Mean & $\begin{array}{r}\text { Standard } \\
\text { Error }\end{array}$ & $\begin{array}{r}\text { Mean Standard } \\
\text { Error }\end{array}$ \\
\hline \hline Husband & & & & & & \\
Age & 49.36 & 9.89 & 51.30 & 8.92 & 49.90 & 9.67 \\
Schooling & 11.46 & 3.30 & 10.38 & 3.47 & 11.16 & 3.38 \\
Non-English & 0.76 & 0.43 & 0.88 & 0.32 & 0.79 & 0.41 \\
Wife & & & & & & \\
Age & & & & & & \\
Schooling & 45.75 & 10.14 & 48.55 & 9.17 & 46.53 & 9.96 \\
Non-English & 11.46 & 2.53 & 10.16 & 2.99 & 11.10 & 2.73 \\
\hline & 0.34 & 0.47 & 0.84 & 0.37 & 0.48 & 0.50 \\
\hline
\end{tabular}

Table 4: Descriptive Statistics for Second-Generation Males and their Wives by Marriage Type

geographic proximity explains a significant portion of endogamy rates, a considerable amount can only be attributed to preferences for marrying within ethnicity.

The cultural adaptability effect implies that tastes for ethnicity decrease as education increases. In terms of Table 3, this suggests that the difference between actual endogamy rates and implied endogamy rates should be decreasing as education increases for both ethnicities. In actuality, however, the difference is slightly increasing in education, but the effect is not statistically significant.

In Table 4, means and standard deviations of second-generation males are shown for various characteristics by whom they marry. Men who marry within their ethnicity have on average one year less of education than their intermarrying counterparts. Their wives follow this pattern almost exactly. For all of the different ethnicities and the population as a whole, education of the husband is positively correlated with education of the wife. Also note that, as implied by the model, the difference in average years of schooling between husband and wife is greater in exogamous couples than in endogamous couples. Men who marry within their ethnicity are slightly older than those who marry out. This suggests a downward trend in ethnic endogamy through time. Wives' ages follow the same pattern. Approximately eighty percent of all second-generation males do not have English as their native language. Not surprisingly, men with a non-English native tongue are more likely to marry within their ethnicity.

Figure 5 graphs endogamy rates by ethnicity and level of education. Ethnicities are ordered on the $\mathrm{x}$ axis by average years of schooling. The darker bars show endogamy rates for people with 
Endogamy Rates by Ethnicity and Education

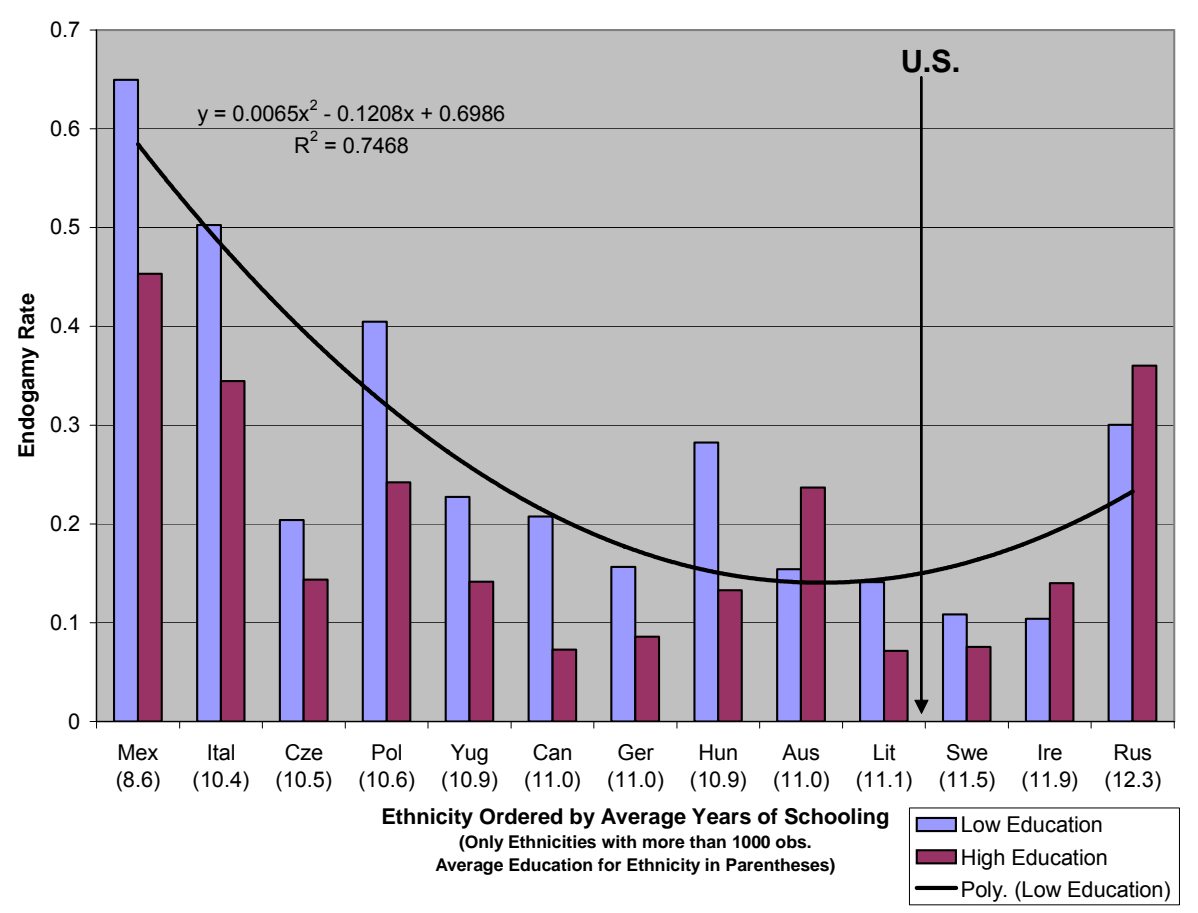

Figure 5: Evidence of Assortative Matching on Education 
education levels above the median for that ethnicity while the lighter bars show endogamy rates for people with education levels below the median. The black line in the middle marks the average level of education in the U.S. as a whole, 11.30. Superimposed on the bar chart is a fitted polynomial through the low education endogamy rates. As predicted by the assortative matching model, the curve has a U shape. That is, the highest endogamy rates are for ethnicities with average education levels furthest away from the average education in the U.S. population. Moreover, for ethnicities with average education levels less than the U.S. average, within ethnicity, highly educated people typically have lower endogamy rates than lowly educated people. The opposite is generally true for ethnicities with average education levels above the U.S. average. This suggests that assortative matching on education does in fact play an important role in explaining endogamy rates. However, for a more complete test, we turn to regression analysis.

\subsection{Empirical Specification and Results}

To disentangle the cultural adaptability effect from the assortative matching effect of education on endogamy, I test for the differential impact of education depending on the average education in one's ethnic group. The following probit model is estimated:

$$
\begin{gathered}
\operatorname{Pr}\left(y_{i j k}=1\right)=\Phi\left(\beta_{0}+\beta_{1} h_{i j k}+\beta_{2} h_{i j k}\left(\overline{h_{j k}^{w}}-\bar{h}_{a k}^{w}\right)+\beta_{3}\left(\overline{h_{j k}^{w}}-\bar{h}_{a k}^{w}\right)\right. \\
\left.+\beta_{4} p_{j k}+\beta_{5} p_{j k}^{2}+\beta_{6} X_{i j k}\right)
\end{gathered}
$$

In this model, $y_{i j k}$ is a dichotomous indicator equal to one if man $i$ in ethnicity $j$ in geographical area $k$ is married within his ethnicity and zero otherwise. In the empirical analysis, years of schooling is used to proxy for $h$, mean group schooling ${ }^{13}$ for $\bar{h}_{e}^{w}$ and mean schooling for $\bar{h}_{a}^{w}$. The

\footnotetext{
${ }^{13}$ Observations with averages constructed from fewer than 50 observations were dropped from the analysis.
} 


\begin{tabular}{|c|c|c|c|}
\hline Endogamy & 1 & 2 & 3 \\
\hline Schooling & $\begin{array}{r}-0.019 \\
(-2.61)^{* *}\end{array}$ & $\begin{array}{r}-0.012 \\
(-1.69)+\end{array}$ & $\begin{array}{l}0.000 \\
(0.04)\end{array}$ \\
\hline Size of Ethnic Group & & $\begin{array}{r}4.506 \\
(5.65)^{\star *}\end{array}$ & $\begin{array}{r}4.162 \\
(5.07)^{* *}\end{array}$ \\
\hline Size of Ethnic Group ${ }^{2}$ & & $\begin{array}{r}-8.550 \\
(-4.58)^{* *}\end{array}$ & $\begin{array}{r}-8.355 \\
(-4.11)^{* *}\end{array}$ \\
\hline $\begin{array}{l}\text { Schooling X } \\
\quad \text { (Mean Group Schooling-Mean Schooling) }\end{array}$ & & & $\begin{array}{r}0.008 \\
(2.11)^{*}\end{array}$ \\
\hline (Mean Group Schooling-Mean Schooling) & & & $\begin{array}{r}-0.110 \\
(-5.05)^{* *}\end{array}$ \\
\hline Age & $\begin{array}{r}0.006 \\
(2.22)^{*}\end{array}$ & $\begin{array}{r}0.008 \\
(3.37)^{* *}\end{array}$ & $\begin{array}{r}0.000 \\
(5.56)^{* *}\end{array}$ \\
\hline Non-English Native Tongue & $\begin{array}{r}0.163 \\
(5.70)^{* *}\end{array}$ & $\begin{array}{r}0.146 \\
(4.54)^{\star *}\end{array}$ & $\begin{array}{r}0.135 \\
(5.39)^{* *}\end{array}$ \\
\hline Observations & 20109 & 20109 & 20109 \\
\hline
\end{tabular}

Robust z-statistics in parentheses

+ significant at $10 \% ;{ }^{*}$ significant at $5 \% ;{ }^{* *}$ significant at $1 \%$

Table 5: Probit Marginal Effects of Schooling on Endogamy

share of the population belonging to $i$ /s ethnicity, $p$, is captured by ethnic group size. The vector of characteristics which capture tastes for marrying within ethnicity, $X$, includes age and non-English native tongue. Tables 5 and 6 report coefficient estimates of variants of equation (10) estimated as probit models. All errors are clustered on ethnicity.

The theoretical model implies that the effect of education through cultural adaptability is always negative while its effect through assortative matching depends on ethnicity. That is, assortative matching implies that an increase in education will lead to a decrease in the probability of marrying within ethnicity for people belonging to low education ethnicities while the opposite is true for those belonging to high education groups. In particular, the larger the difference between average education in the ethnic group and the rest of the population, the stronger will be the assortative matching effect. Thus, we expect $\beta_{1}<0$ if the cultural adaptability effect is true and $\beta_{2}>0$ if the assortative matching effect is true. ${ }^{14}$ By including the proportion of the population

\footnotetext{
${ }^{14}$ Endogeneity may be of some concern in this analysis. For example, bachelors who care more about ethnicity may invest less in their own human capital. This, however, works against me in that it increases the probability of finding a significant cultural adaptability effect when in fact, cultural adaptability does not play a strong role in the marriage market. A potentially more problematic concern is if immigrants with high preferences for ethnicity in high education ethnicities obtain more education in order to facilitate finding a same-ethnicity spouse while those in low education ethnicities obtain less education for marriage market purposes. This story, however, only further
} 


\begin{tabular}{|c|c|c|c|}
\hline Endogamy & Country & State & County Group \\
\hline Schooling & $\begin{array}{r}0.001 \\
(0.1)\end{array}$ & $\begin{array}{l}0.005 \\
(0.89)\end{array}$ & $\begin{array}{l}0.000 \\
(0.04)\end{array}$ \\
\hline Size of Ethnic Group & $\begin{array}{l}30.724 \\
(2.03)^{*}\end{array}$ & $\begin{array}{r}9.12 \\
(4.23)^{\star *}\end{array}$ & $\begin{array}{r}4.162 \\
(5.07)^{\star *}\end{array}$ \\
\hline Size of Ethnic Group ${ }^{2}$ & $\begin{array}{r}-883.444 \\
(-1.53)\end{array}$ & $\begin{array}{c}-56.891 \\
(-2.58)^{\star *}\end{array}$ & $\begin{array}{r}-8.355 \\
(-4.11)^{\star *}\end{array}$ \\
\hline $\begin{array}{l}\text { Schooling X } \\
\text { (Mean Group Schooling-Mean Schooling) }\end{array}$ & $\begin{array}{r}0.009 \\
(1.90)+\end{array}$ & $\begin{array}{r}0.009 \\
(2.23)^{*}\end{array}$ & $\begin{array}{r}0.008 \\
(2.11)^{*}\end{array}$ \\
\hline (Mean Group Schooling-Mean Schooling) & $\begin{array}{r}-0.155 \\
(-3.83)^{\star *}\end{array}$ & $\begin{array}{r}-0.125 \\
(-4.54)^{* *}\end{array}$ & $\begin{array}{r}-0.11 \\
(-5.05)^{\star *}\end{array}$ \\
\hline Age & $\begin{array}{r}0.007 \\
(6.39)^{\star *}\end{array}$ & $\begin{array}{r}0.009 \\
(5.76)^{\star *}\end{array}$ & $\begin{array}{r}0.009 \\
(5.56)^{\star *}\end{array}$ \\
\hline Non-English Native Tongue & $\begin{array}{r}0.103 \\
(4.56)^{\star *}\end{array}$ & $\begin{array}{r}0.114 \\
(5.50)^{\star *}\end{array}$ & $\begin{array}{r}0.135 \\
(5.39)^{\star *}\end{array}$ \\
\hline Observations & 39943 & 29041 & 20109 \\
\hline
\end{tabular}

Table 6: Probit Marginal Effects of Schooling on Endogamy for Different Geographic Partitions

in his ethnicity living in this geographical area, any effect of education will be purged of the enclave effect. Although the formal proof is not included in this paper, the size of the ethnic group increases endogamy, but at a decreasing rate. This implies that $\beta_{4}>0$ and $\beta_{5}<0$.

According to the enclave effect, as education increases, people tend to move out of ethnic enclaves and so have a lower probability of meeting potential spouses of the same ethnicity. The PUMs does not contain information about whether people grew up in ethnic enclaves and, if so, when they moved out. Thus, it is not possible to measure the enclave effect directly. However, if I assume that after acquiring education, people move to where they are living at the time of the survey, search for a spouse, marry, and remain in roughly the same location, the size of the ethnic group variable would completely purge $\beta_{1}$ and $\beta_{2}$ of the enclave effect of education. Admittedly, these conditions are quite strong, but biases resulting if these assumptions do not hold are not large. They will be discussed shortly.

Table 5 compares marginal effects from different specifications of a probit model conducted at the county group level. Notice that when education and controls for preferences for marrying within

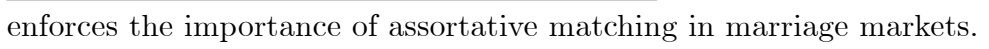


ethnicity (Age and non-English native tongue) are the only variables included on the right hand side of the regression, education has a negative and significant impact on the probability of in-marriage. Regression results suggest that one more year of education leads to a .02 decrease in the probability of marrying within ethnicity. According to the model, the effect of education could be small either because there is simply little effect of education on the probability of interethnic marriage or because the different avenues through which education affects intermarriage (i.e. cultural adaptability effect, assortative matching on education effect, and enclave effect) have opposing effects that cancel each other out. Controls for endogamy preference have the expected signs. That is, second-generation immigrants with a non-English mother tongue are significantly more likely to marry within their ethnicity, and older people are more likely to marry within ethnicity.

When controlling for ethnic group size in specification (2), the effect of education alone (cultural adaptability effect) decreases by almost 50 percent and is only significant at the 10 percent level. As expected, the larger the ethnic representation in the county group in which a second-generation immigrant lives, the more likely he is to marry within his ethnicity. The negative coefficient on the square of ethnic group size suggests that the slope is decreasing in group size as predicted by the model.

The interaction term is added in specification (3) to differentiate the assortative matching effect from the cultural adaptability effect. According to the assortative matching theory, an increase in education has different effects depending on the ethnicity to which a person belongs. In fact, as seen in Table 5, leaving constant the portion of the effect of education that changes depending upon the ethnicity of the person, the effect of education alone is not statistically different from 
zero. Thus, there is no support for the cultural adaptability effect of education. ${ }^{15,16}$

Specific examples are useful for interpreting the magnitude of the assortative matching effect of education. The effect of an increase in education has the greatest impact on second-generation immigrants from countries whose mean education values are very different from the rest of the population. For example, a Mexican second-generation male with an eighth grade education, the average education for Mexicans, will decrease his probability of marrying a Mexican by 2.36 percentage points, $0+.008(8.35-11.30)$ by acquiring one additional year of education. (Mexicans have an average of 8.35 years of education while Americans have an average of 11.30.) This suggests that his decision to finish high school leads to an 8.4 percentage point increase in the probability of intermarriage. On the other hand, for an average Russian second-generation immigrant, an additional year of education increases his probability of intramarriage by 0.79 percentage points, $0+.008(12.29-11.30)$. Finishing college leads to a 2.94 percentage point increase in the probability of marrying another Russian.

As suggested above, some caution must be used in the interpretation of these results because two problems result from the poor measure of the opportunity of meeting others of the same ethnicity. First, the size of the ethnic group within an immigrant's close geographic proximity is endogenous in that people choose where to live, potentially for reasons related to the marriage market. If with more education, immigrants become more accepting of differences and thus more likely to both

\footnotetext{
${ }^{15}$ It is unclear, however, whether parents' country of birth is the most appropriate measure of ethnicity. There are many countries with very different cultures within them, and these countries are more likely to have lower endogamy rates all else equal. For example, a Russian Jew may have more in common ethnically with a Polish Jew than a non-Jewish Russian. If this heterogeneity within countries is correlated with education, the coefficients on education may be biased. As a test of whether the coefficients are biased, I included a measure of religious pluralism (obtained from Barro and McCleary 2003) in the empirical specification. As expected, the coefficient on religous pluralism had a negative sign but the coefficients on the education variables remain almost exactly the same.

${ }^{16}$ There may be some concerns about endogeneity in this empirical analysis. For example, bachelors who care more about ethnicity of their spouses may invest less in their own human capital. This would bias the cultural adaptability coefficient downward. However, because the assortative matching effect has little empirical support anyway, this potential bias only accentuates my results. A potentially more problematic concern is if immigrants who want to marry co-ethnics acquire more education if they are in high education ethnicities and less education if they are in low education ethnicities. However, immigrants will only adopt this strategy if assortative matching on education is an important element of the marriage market. Thus, my central result remains.
} 
move away from ethnic enclaves and marry an American, the cultural adaptability coefficient may be biased towards zero. In this scenario, just as predicted by the cultural adaptabililty hypothesis, education decreases preferences for ethnicity, but it may only affect marriage patterns through people's decisions about where to live and thus would not be captured in this analysis. The empirical literature suggests that education always has a nonnegative effect on outmigration, and so it is unlikely that the coefficient capturing the assortative matching effect is biased. For that coefficient to be biased, the effect of education on outmigration should depend on the ethnic group to which immigrants belong. Thus, we can interpret the cultural adaptability coefficient either as an upperbound of the true effect of education on preferences for ethnicity or as the cultural adabtability effect purged of its effect through location decisions.

Beyond these problems is the issue that the size of the ethnic group in this analysis is measured at the time and place of the survey as opposed to the time and place when and where married immigrants were searching for a spouse. It is conceivable that even immigrants who marry Americans for reasons unrelated to education or preferences for ethnicity are more likely to leave enclaves because their spouses are not bound to the enclave. Alternatively, immigrants may have been predominantly exposed to Ethnics when they were searching for a spouse but because of their education, they may have both married an American (by either the cultural adaptability or assortative matching effect) and moved away from their enclave post-marriage.

The signs of the bias differ depending on which story is told, but a few empirical techniques suggest that the bias is not large. First, the empirical analysis is run solely on those couples where the husband is living in the same county that he was living in five years previous to the survey date but the wife moved counties within the five years before the survey date. The presumption is that these couples married within that five year period and that the husband is facing roughly the same opportunity for endogamous marriage as he was while searching for a spouse. Estimating 
equation (10) on this limited sample, I find that the coefficients on the education variables remain roughly the same in terms of size and significance, suggesting that although there may be a bias, it is not very large. I also ran the empirical analysis on the entire sample using the size of the ethnic group (at the time of the survey) in the man's state of birth, and again, the results do not change qualitatively. This technique does not control for the enclave effect in that it does not capture people's migration decisions as a result of an increase in education. However, if people are more likely to search for a spouse in their state of birth, necessarily pre-marriage, than in their state of residence at the time of the survey, then this measure of opportunity will be the more appropriate one. Moreover, the fact that the coefficients on education do not change suggests that my imperfect control for the enclave effect is not significantly biasing the results. ${ }^{17}$

It is not necessarily the case that the county group is the most relevant marriage market. Table 6 shows that for three different geographic partitions, assortative matching is the most important avenue through which education affects endogamy. I have also conducted the analysis above on marriage decisions of women and results are qualitatively the same.

\section{Testing the Validity of the Model}

The previous section presented a spouse-search model which provided a way to differentiate the mechanisms through which human capital can affect marriage decisions. The validity of this identification strategy, however, rests on the soundness of the model from which it was derived. In this section, I provide support for the model by deriving some of its additional implications and testing them with data.

\footnotetext{
${ }^{17}$ Regression coefficient tables for both of these empirical tests are available from the author upon request.
} 


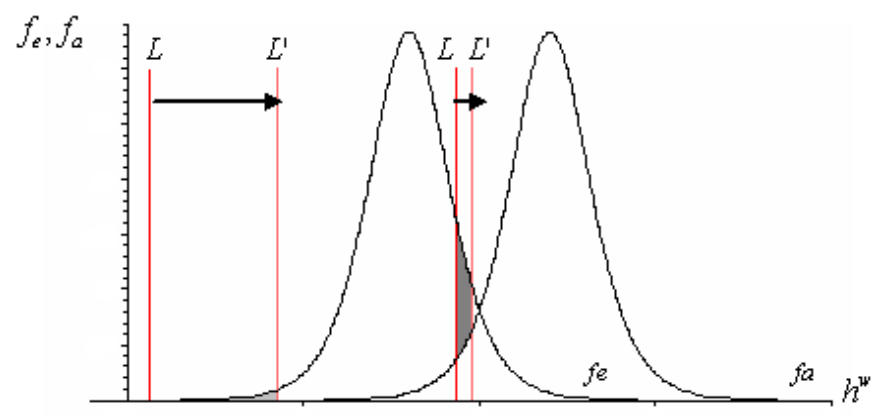

Figure 6: Change in the Probability of Intramarriage when $p$ is High and $h$ is Low

\subsection{Extremely High or Low Values of Spouse-Searcher Education}

\subsubsection{Theory}

Although it is very intuitive that an increase in education yields an increase in endogamy for people in high education ethnicities and a decrease for people in low education ethnicities, the model presented in Section 2 does not always predict this relationship. As formally described in Appendix B, even if variances in education are equal in the two populations, whether or not this relationship holds depends on two factors: the spouse-searcher's education, $h$, and the probability, $p$, that he is matched with someone of his ethnicity. Specifically, an increase in education can result in an increase in endogamy even for people in low education ethnicities if $p$ is high enough and $h$ is low enough or if $p$ is low enough and $h$ is high enough. Similarly, an increase in education can result in a decrease in endogamy for those in high education ethnicities if $p$ and $h$ are either both low enough or both high enough. For simplicity of exposition, I will continue under the assumptions that ethnicity of a spouse does not enter immigrants' utility functions, that is $T=0$, and that variances of the education distributions of Ethnics and Americans are equal.

For pedagogical purposes, I will start with the case where $p$ is neither high nor low but exactly 1/2 : Ethnics are just as likely to come across other Ethnics as they are Americans. This suggests 


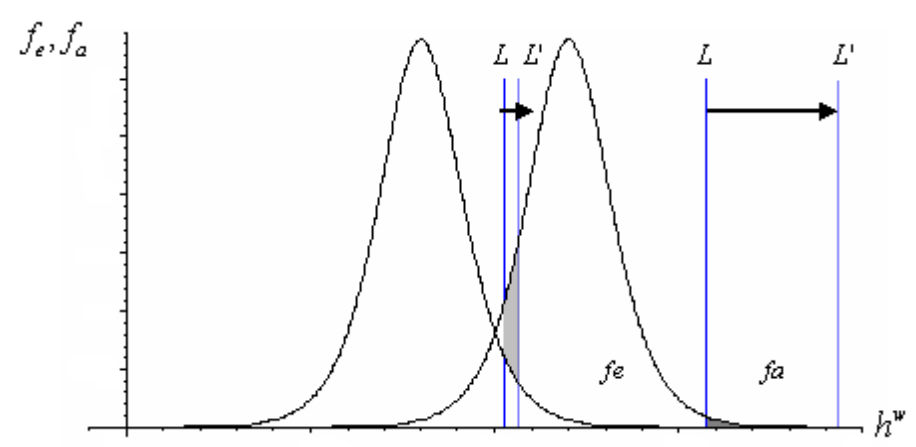

Figure 7: Change in the Probability of Intramarriage when $p$ is Low and $h$ is High

that the level of education corresponding with expected utility in the second period is fairly close to the education level corresponding with the intersection of the Ethnic and American education distributions. Moreover, it implies that the acceptance region limits always lie on opposite sides of the intersection (A formal proof is provided in Appendix B). Thus, even if a person in a low education ethnicity has a very low level of education, the rightward shift of his upper limit will always result in an increase in the probability of marrying an American. Similarly, if his education is very high, the rightward shift of the lower limit always results in a decrease in the probability of marrying an Ethnic.

Symmetric results follow when Ethnics typically have more education than Americans. The rightward shift of the left hand limit will result in a decrease in the probability of marrying an American even if the man's education level is very high. The rightward shift of the right hand limit will result in an increase in the probability of marrying an Ethnic if the man's education level is very low. To conclude, if $p=1 / 2$, an increase in $h$ will always lead to a decrease in endogamy for people in low education ethnicities and an increase in endogamy for people in high education ethnicities. This will not always be the case if $p \neq 1 / 2$.

Figures 6 and 7 are graphical representations of what can happen when $h$ increases if $p \neq 1 / 2$. Consider a spouse-searcher with a very low level of education in a low education ethnicity living 
in an area where he is considerably more likely to meet an Ethnic than an American. Figure 6 illustrates acceptance regions for the case where $p$ is high and $h$ is low. $L L$ depicts the original acceptance region and $L^{\prime} L^{\prime}$ shows how the region shifts with an increase in education. Notice that for both levels of education, the acceptance regions lie over education levels that Ethnics are more likely to have than Americans. ${ }^{18}$ As seen in Figure 6, this means that an increase in education could actually result in an increase in the probability of marrying an Ethnic. The reason is that the increase in the probability of marrying an Ethnic due to the rightward shift of the right hand limit of the acceptance region, the darker shaded area in Figure 6, is greater than the decrease in the probability resulting from the rightward shift of the left hand limit, the lightly shaded area. More intuitively, because of the increase in the number of Ethnic marriages in the first period, fewer people are randomly matched with an American in the second period and thus the probability of ending up with someone of the same ethnicity actually increases. ${ }^{19}$

Using a similar logic, again under the assumption that Ethnics typically have less education than Americans, an increase in the probability of marrying an Ethnic could result for a very well educated man in a low education ethnicity if the probability of being matched with an Ethnic is very low. Figure 7 depicts the same density functions as Figure 6, but acceptance regions are shown for the case where $p$ is low and $h$ is high. This means that the Ethnic spouse-searcher has a level of education that more closely resembles the American average education than the Ethnic average and that he lives in an area with few fellow Ethnics. In this scenario, the entire acceptance

\footnotetext{
${ }^{18}$ The condition that he is very low educated in a low education ethnicity implies that he is not likely to accept an American in the first period because Americans typically have much higher education levels than he does. The condition that probability of meeting someone of his own ethnicity is very high implies that the level of education corresponding with the expected utility in the second period is fairly close to the mean of the Ethnic distribution. This implies that the right-hand limit of the acceptance region lies to the left of the intersection of the two distributions.

${ }^{19}$ If spouse-searchers can choose to remain single if they end up with a particularly bad match, then this reversal in sign will not be as pronounced. The initial increase in endogamy in this scenario occurs because spouse-searchers become more likely to find acceptable matches in the first period. If the size of the ethnic group is large and education is low, these first period matches are most likely Ethnic. Thus, spouse-searchers become less likely to be randomly paired with an American who is most likely a bad match. If spouse-searchers can choose to remain single, then the particularly bad Ethnic-American matches will not form to begin with and so the increase in endogamy will not be as pronounced.
} 


\begin{tabular}{ccccc}
\hline & \multicolumn{2}{c}{$\bar{h}_{e}^{w}<\bar{h}_{a}^{w}$} & \multicolumn{2}{c}{$\bar{h}_{e}^{w}>\bar{h}_{a}^{w}$} \\
\hline & h low & h high & h low & h high \\
\hline \hline$p>\frac{1}{2}$ & $\downarrow$ & $\uparrow$ & $\uparrow$ & $\downarrow$ \\
$p=\frac{1}{2}$ & $\downarrow$ & $\downarrow$ & $\uparrow$ & $\uparrow$ \\
$p<\frac{1}{2}$ & $\uparrow$ & $\downarrow$ & $\downarrow$ & $\uparrow$ \\
\hline
\end{tabular}

Table 7: Effect of an Increase in Education by Education Level and Size of Ethnic Group

region lies over levels of education more common among Americans than Ethnics. As shown in Figure 7, the increase in the probability of accepting an American in the first period resulting from the rightward shift of the right hand limit of the acceptance region, the lightly shaded area, is less than the decrease resulting from the rightward shift of the left hand limit, the darker shaded area. Again, with fewer acceptances of Americans in the first period, people are more likely to become randomly matched with Ethnics in the second period and so the probability of marrying an Ethnic by the end of the game actually increases.

Although not shown here, it is fairly straightforward to see that the results are reversed when Ethnics have more education than Americans. All of this information is summarized in Table 7.

\subsubsection{Empirical Tests}

In order to formally test the implication that the effect of education depends not only on the ethnic group to which one belongs, but also on the interaction between the size of this group and one's level of education, regression analysis is used. The model implies that an increase in education for immigrants in low education ethnicities with either very high levels of education in small ethnic groups or low levels of education in large ethnic groups leads to an increase in the probability of marrying within ethnicity. Conversely, an increase in education for immigrants in high education ethnicities with either very high levels of education in large ethnic groups or low levels of education in small ethnic groups leads to a decrease in the probability of marrying within ethnicity. To test 
these implications, I divide the sample according to whether average levels of education are greater than or less than average American levels and then run probit regressions of the following model on each of the two samples:

$$
\operatorname{Pr}\left(y_{i j k}=1\right)=\Phi\left(\gamma_{1} h_{i j k}+\gamma_{2} h_{i j k}^{2}+\gamma_{3} p_{j k} h_{i j k}+\gamma_{4} p_{j k} h_{i j k}^{2}+\gamma_{5} p_{j k}+\gamma_{6} X_{i j k}\right)
$$

A strict interpretation of the theoretical model implies that for both samples $\gamma_{1}<0, \gamma_{2}>0$, $\gamma_{3}>0$ and $\gamma_{4}<0$. These signs imply a convex relationship between education and endogamy when the size of the ethnic group is small and a concave relationship when the size is large. In fact, just as predicted by the theoretical model, certain parameter values are consistent with a positive relationship between education and endogamy for some specific immigrants in low education ethnicities. Likewise, certain parameter values obtained from the high education sample can imply a negative relationship between education and endogamy for certain immigrants. Since the effect of education on endogamy should generally be negative for people in low education ethnicities and positive for those in high education ethnicities, the size of the coefficients should differ in the two samples, but the theoretical model implies the same signs for both high and low education ethnicities.

Tables 8 and 9 present marginal effects for probit regressions run on low and high education ethnicities respectively at the county group level. That is, the size of the ethnic group variable was constructed with the population of the county group as a base. Consistent with the previous set of regressions, an increase in education leads to a decrease in endogamy rates for low education ethnicities (Table 8) and an increase for high education ethnicities (Table 9): One more year of education leads to a 0.04 decrease in the probability of marrying within ethnicity for people in low education ethnicities and a 0.01 increase in the probability for people in high education ethnicities 
(although this increase is insignificant) when controlling for only age and the square of education (Column 1).

More noteworthy, however, is what occurs when the education-ethnicity size interactions are included in specifications (3) and (4). Coefficients of interest all have the expected sign and, except for the square of education, are all significant at the 5 percent level for low education ethnicities. Three zones can be constructed using the estimates in Table 8. When the size of the ethnic group is less than 0.016, education decreases the probability of endogamy at a decreasing rate. When the size of the ethnic group is between 0.016 and 0.15 , education continues to decrease endogamy but at an increasing rate. In fact, when the size of the ethnic group is greater than 0.15 , regression results imply an initial increase and subsequent decrease in endogamy.

Although the existence of these three zones is consistent with the theory, the model only predicts an increase in endogamy for people in low education ethnicities when $p>1 / 2$. This is an issue in the analysis since for no ethnicity-county group combination in the data is the size of ethnic group greater than a half. This does not mean that the actual probability of meeting someone of the same ethnicity is always necessarily less than a half. It is reasonable to believe, for example, that the marriage market is concentrated at the neighborhood level as opposed to the county group level. Although I do not use data at the neighborhood level I can infer from Borjas' (1995) measures of size of ethnicity in the neighborhood that neighborhood concentrations are on average about three times as high as county group concentrations (See Table 3 for Mexican and Russian examples). This suggests that immigrants facing a 15 percent probability of encountering a co-ethnic in their county groups actually face around a 45 percent probability of encountering a co-ethnic in their neighborhoods. This is certainly very close to the one half that is implied by the theory.

As can be seen in Table 9, three zones can also be constructed for high education ethnicities. When the size of ethnic group is less than 0.0004, education increases endogamy at a decreasing 
rate. Admittedly, this is inconsistent with the theoretical predictions of the model, but perhaps sampling error is a greater concern in county groups with virtually no immigrants and children of immigrants. When the size of the ethnic group is between 0.0004 and 0.048 , an increase in education increases endogamy at an increasing rate. Finally, when the size of the ethnic group is greater than 0.048 , an increase in education results in a decrease in endogamy for very low levels of education, but for high enough education levels, the effect is positive. This is consistent with the implications of the model when $p>1 / 2$. Again, it could be that because of ethnic segregation at the neighborhood level, second-generation immigrants living in county groups with co-ethnic proportions greater than 0.04 actually face a probability of meeting someone of the same ethnicity which is greater than a half.

Because these results could be due simply to the high collinearity between the square term of education and its linear counterpart, spline regressions were run with corresponding specifications. Results were similar.

\subsection{Unequal Variances}

Until now, variances of the education distributions have been assumed to be the same in the two populations, but this is not necessarily the case. Table 10 shows standard deviations of education for the ethnicities used in this analysis. Notice that half of the ethnicities have standard deviations which are statistically different from the standard deviation of education in the U.S. population as a whole.

Through the use of some examples, I will examine the effect of differences in variances on the implications drawn from the theoretical model. The proof of the cultural adaptability effect does not change without the equal variance assumption: Regardless of whether variances are the same, an increase in education always leads to a decrease in endogamy through the cultural adaptability 


\begin{tabular}{|c|c|c|c|c|}
\hline Endogamy & 1 & 2 & 3 & 4 \\
\hline Schooling & $\begin{array}{r}-0.042 \\
(-6.59)^{\star *}\end{array}$ & $\begin{array}{r}-0.035 \\
(-4.69)^{\star *}\end{array}$ & $\begin{array}{r}-0.033 \\
(-3.11)^{\star *}\end{array}$ & $\begin{array}{r}-0.018 \\
(-2.02)^{*}\end{array}$ \\
\hline Schooling $^{2}$ & $\begin{array}{r}0.000 \\
(1.92)+\end{array}$ & $\begin{array}{l}0.000 \\
(0.83)\end{array}$ & $\begin{array}{l}0.000 \\
(0.73)\end{array}$ & $\begin{array}{l}0.000 \\
(0.35)\end{array}$ \\
\hline Size of Ethnic Group & & $\begin{array}{r}4.152 \\
(4.88)^{* *}\end{array}$ & $\begin{array}{r}2.938 \\
(2.94)^{* *}\end{array}$ & $\begin{array}{r}3.244 \\
(3.80)^{* *}\end{array}$ \\
\hline Size of Ethnic Group ${ }^{2}$ & & $\begin{array}{r}-8.521 \\
(-4.02)^{\star *}\end{array}$ & $\begin{array}{r}-7.07 \\
(-2.86)^{\star \star}\end{array}$ & $\begin{array}{r}-7.254 \\
(-3.57)^{\star \star}\end{array}$ \\
\hline Schooling*Group Size & & & $\begin{array}{r}0.108 \\
(3.01)^{\star \star}\end{array}$ & $\begin{array}{r}0.118 \\
(3.48)^{\star \star}\end{array}$ \\
\hline Schooling ${ }^{2 *}$ Group Size & & & $\begin{array}{r}-0.005 \\
(-3.61)^{\star *}\end{array}$ & $\begin{array}{r}-0.006 \\
(-4.90)^{* \star}\end{array}$ \\
\hline Mean Group Schooling- & & & -0.046 & -0.069 \\
\hline $\begin{array}{l}\text { Mean Schooling } \\
\text { Non-English Native Tongue }\end{array}$ & & & $(-2.79)^{\star \star}$ & $\begin{array}{c}(-7.61)^{\star \star} \\
0.161 \\
(4.09)^{\star \star}\end{array}$ \\
\hline Age & & & & $\begin{array}{r}0.011 \\
(10.42)^{\star \star}\end{array}$ \\
\hline Observations & 14720 & 14720 & 14720 & 14720 \\
\hline
\end{tabular}

Robust z-statistics in parentheses

+ significant at $10 \%$; * significant at $5 \% ;{ }^{* *}$ significant at $1 \%$

Table 8: Probit Marginal Effects of Education and Size of Ethnic Group Interactions for Low Education Ethnicities

\begin{tabular}{|c|c|c|c|c|}
\hline Endogamy & 1 & 2 & 3 & 4 \\
\hline Schooling & $\begin{array}{l}0.010 \\
(1.04)\end{array}$ & $\begin{array}{l}0.014 \\
(1.33)\end{array}$ & $\begin{array}{r}0.055 \\
(2.01)^{\star}\end{array}$ & $\begin{array}{r}0.074 \\
(1.94)+\end{array}$ \\
\hline Schooling $^{2}$ & $\begin{array}{r}0.000 \\
0.23)\end{array}$ & $\begin{array}{r}0 \\
(0.45)\end{array}$ & $\begin{array}{l}-0.002 \\
(-1.60)\end{array}$ & $\begin{array}{l}-0.002 \\
(-1.61)\end{array}$ \\
\hline Size of Ethnic Group & & $\begin{array}{r}2.17 \\
(0.42)\end{array}$ & $\begin{array}{l}12.568 \\
(1.75)+\end{array}$ & $\begin{array}{l}13.093 \\
(1.88)+\end{array}$ \\
\hline Size of Ethnic Group ${ }^{2}$ & & $\begin{array}{r}15.566 \\
(0.23)\end{array}$ & $\begin{array}{r}25.099 \\
(0.34)\end{array}$ & $\begin{array}{r}13.475 \\
(0.17)\end{array}$ \\
\hline Schooling ${ }^{\star}$ Group Size & & & $\begin{array}{r}-1.556 \\
(-3.47)^{\star *}\end{array}$ & $\begin{array}{r}-1.539 \\
(-2.61)^{* *}\end{array}$ \\
\hline Schooling ${ }^{2 \star}$ Group Size & & & $\begin{array}{r}0.051 \\
(2.49)^{*}\end{array}$ & $\begin{array}{r}0.05 \\
(2.00)^{*}\end{array}$ \\
\hline $\begin{array}{l}\text { Mean Group Schooling- } \\
\text { Mean Schooling }\end{array}$ & & & $\begin{array}{r}0.084 \\
(1.68)+\end{array}$ & $\begin{array}{l}0.071 \\
(1.24)\end{array}$ \\
\hline Non-English Native Tongue & & & & $\begin{array}{r}0.074 \\
(2.01)^{*}\end{array}$ \\
\hline Age & & & & $\begin{array}{r}0.007 \\
(1.73)+\end{array}$ \\
\hline Observations & 5389 & 5389 & 5389 & 5389 \\
\hline
\end{tabular}

Robust z-statistics in parentheses

+ significant at $10 \% ;{ }^{*}$ significant at $5 \% ;{ }^{* *}$ significant at $1 \%$

Table 9: Probit Marginal Effects of Education and Size of Ethnic Group Interactions for High Education Ethnicities 


\begin{tabular}{ll}
\hline Ethnicity & Standard Deviation \\
\hline \hline Sweden & $2.72^{*}$ \\
Yugoslavia & $2.77^{*}$ \\
Ireland & $2.78^{*}$ \\
Czech & $2.79^{*}$ \\
Italy & $2.84^{*}$ \\
Hungary & $2.87^{*}$ \\
Germany & 3.03 \\
Lithuania & 3.03 \\
Poland & 3.04 \\
Canada & 3.06 \\
Russia & 3.09 \\
Mexico & $3.98^{*}$ \\
\hline *Statistically different from U.S. \\
standard deviation at 5\% level. \\
U.S. Standard Deviation: 3.05
\end{tabular}

Table 10: Education Standard Deviations by Ethnicity

effect. The proof of the assortative matching effect, however, is responsive to this assumption. For simplicity, again assume that $T=0$.

\subsubsection{Theory}

Recall that the probability of endogamy can be written,

$$
\begin{aligned}
\operatorname{Pr}(\text { Endogamy })= & p+p(1-p)\left\{\left[F_{e}(h+\sqrt{-R})-F_{e}(h-\sqrt{-R})\right]-\right. \\
& {\left.\left[F_{a}(h+\sqrt{-R})-F_{a}(h-\sqrt{-R})\right]\right\} }
\end{aligned}
$$

The major effect of dropping the equal variance assumption will come from the difference in shape of the education distributions, $F_{e}$ and $F_{a}$. Although the variances do enter the reservation utility (the larger the variances, the lower the reservation utility), this is a second order effect. Figure 8 depicts probability density functions for the case where Ethnics have a lower average but a higher variance in education than Americans. For simplicity, I assume that $p=1 / 2$ so that, as explained in the previous section, the effect of an increase in education is unambiguous if variances are equal.

It should be clear from Figure 8 that because Ethnics typically have lower levels of education than Americans, an increase in education of the spouse-searcher typically results in the acceptance 
region lying over education levels more common among Americans. However, as shown by the acceptance regions in the diagram, when the spouse-searcher has a high enough level of education, an increase actually leads to an increase in the probability of marrying an Ethnic. The increase in the probability of marrying an Ethnic resulting from the shift of the right hand limit (darker shaded region) is greater than the decrease in the probability resulting from the shift of the left hand limit (lightly shaded region). Because the Ethnic distribution has a larger variance, it is easier to meet an Ethnic with a very extreme (high) level of education even though Americans typically have higher education levels.

Figure 9 depicts distributions with the same means as Figure 8 but the variances are reversed. When Americans have the larger variance, again it is true that in general an increase in education leads to a decrease in endogamy, but for spouse-searchers with very low levels of education, an increase can actually lead to an increase in endogamy. Spouse-searchers with extremely low levels of education are willing to marry those Americans with extremely low levels of education. With an increase in education, these spouse-searchers become unwilling to marry these Americans and so they become more likely to marry Ethnics. In terms of the diagram, the increase in the probability of marrying an American (depicted by the darker shaded region) is smaller than the decrease in the probability of marrying an American (depicted by the lightly shaded region.)

For ethnicities with average education levels above that of the American average, the basic relationships remain the same but the probability of in-marriage is typically increasing as opposed to decreasing. When the Ethnic variance is larger than the American variance, an increase in education can lead to a decrease in endogamy for men with low levels of education. Similarly, when the Ethnic variance is smaller than the American variance, an increase in education can lead to a decrease in endogamy for men with very high levels of education. All of these results are summarized in Table 11. 


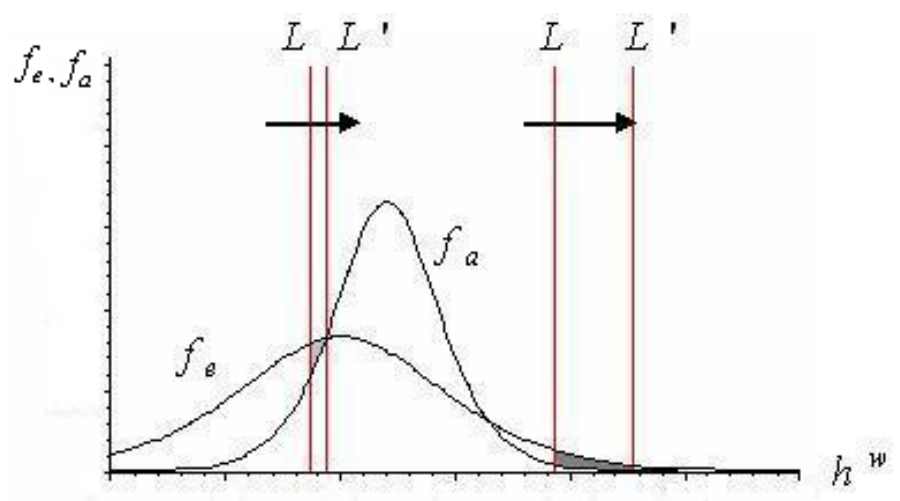

Figure 8: Effect of Education in a Low Education Ethnicity With High Education Variance

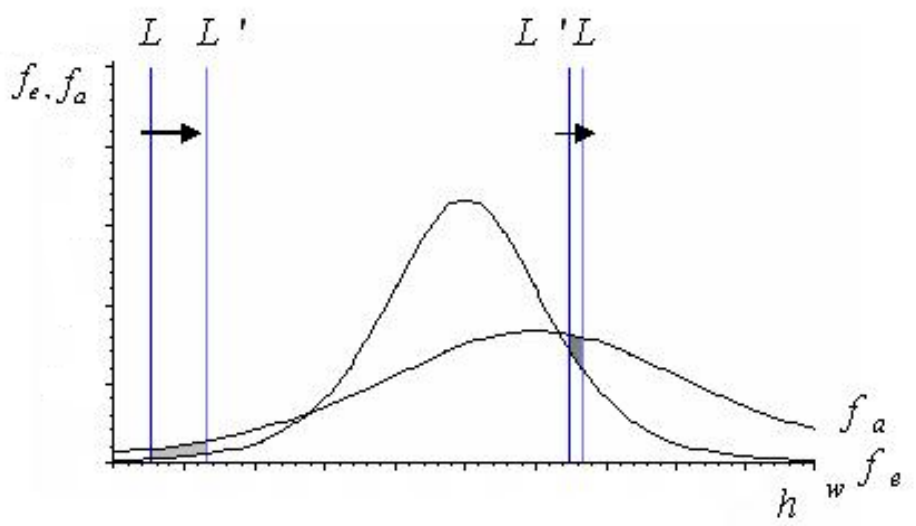

Figure 9: Effect of Education in a Low Education Ethnicity With Low Education Variance

\begin{tabular}{ccccc}
\hline & \multicolumn{2}{c}{$\bar{h}_{e}^{w}<\bar{h}_{a}^{w}$} & \multicolumn{2}{c}{$\bar{h}_{e}^{\omega}>\bar{h}_{a}^{w}$} \\
\hline & h low & h high & h low & h high \\
\hline \hline$\sigma_{e}^{2}>\sigma_{a}^{2}$ & $\downarrow$ & $\uparrow$ & $\uparrow$ & $\downarrow$ \\
$\sigma_{e}^{2}=\sigma_{a}^{2}$ & $\downarrow$ & $\downarrow$ & $\uparrow$ & $\uparrow$ \\
$\sigma_{e}^{2}<\sigma_{a}^{2}$ & $\uparrow$ & $\downarrow$ & $\downarrow$ & $\uparrow$ \\
\hline
\end{tabular}

Table 11: Effect of an Increase in Education by Education Standard Deviation 


\subsubsection{Empirical Tests}

To test these implications, again I divide the sample according to whether average levels of education are greater than or less than the average American education and then run probit regressions of the following model on each of the two samples:

$$
\begin{gathered}
\operatorname{Pr}\left(y_{i j k}=1\right)=\Phi\left(\theta_{1} h_{i j k}+\theta_{2} h_{i j k}^{2}+\theta_{3} h_{i j k} I_{\left(\sigma_{j k}>\sigma_{a k}\right)}+\theta_{4} h_{i j k}^{2} I_{\left(\sigma_{j k}>\sigma_{a k}\right)}+\right. \\
\left.\theta_{5} I_{\left(\sigma_{j k}>\sigma_{a k}\right)}+\theta_{6} p_{j k}+\theta_{7} p_{j k}^{2}+\theta_{8} X_{i j k}\right)
\end{gathered}
$$

where $\sigma_{j k}$ is the standard deviation of education in ethnic group, $j$, in county group, $k$, and $I_{\left(\sigma_{j k}>\sigma_{a k}\right)}$ is a dichotomous variable equal to one if $\sigma_{j k}>\sigma_{a k}$ and zero otherwise. The model predicts that for both samples $\theta_{1}>0, \theta_{2}<0, \theta_{3}<0$ and $\theta_{4}>0$. This is because for both high and low education ethnicities, an increase in $h$ leads to an initial decrease in endogamy and a subsequent increase if $\sigma_{j k}>\sigma_{a k}$, but an initial increase and subsequent decrease if $\sigma_{j k}<\sigma_{a k}$. Since the effect of education on endogamy should generally be negative for people in low education ethnicities and positive for those in high education ethnicities, the size of the coefficients should differ in the two samples, but the theoretical model implies the same signs for both high and low education ethnicities.

Tables 12 and 13 present marginal effects for probit regressions run on low and high education ethnicities respectively at the county group level. Again, column (1) shows that an increase in education leads to a decrease in endogamy rates for low education ethnicities (Table 12) and an increase for high education ethnicities (Table 13), but the coefficients are not significant. Educationstandard deviation interactions are added in specification (2). For low education ethnicities, the coefficients of interest all have the expected signs and all but $\theta_{1}$ are statistically significant. For high education ethnicities, however, no coefficient is statistically different from zero in the second 
column.

One may notice that this empirical specification and the expected signs of the parameters mirror those of the size of ethnicity implication in the previous section. If education-ethnicity size interactions are not included in the regression, the coefficients on education-standard deviation interactions could be biased if standard deviation and ethnicity size are correlated. Thus, in specification 3, both sets of interactions are included. Note that for low education ethnicities, the coefficients on the size of the ethnic group interactions and standard deviation interactions remain significant and maintain the expected sign patterns. For high education ethnicities, the coefficients remain insignificant. This suggests that variances in education of ethnic groups are not sufficiently different from the variance in the American distribution to result in the patterns described above. Inequalities ?? and 2 also hold reconfirming that in general, an increase in education leads to a decrease in endogamy for people in low education ethnicities, but an increase in endogamy for those in high education ethnicities.

\section{Conclusion}

An important channel through which intergenerational assimilation occurs, arguably the most important, is marriage to a native. This paper examines the effect of human capital on the intermarriage decisions of second-generation immigrants.

Three avenues through which education affects the likelihood of intermarriage are presented in this paper. The cultural adaptability effect suggests that educated people are better able to adapt to different customs and cultures. Since immigrants with more human capital have a better "technology" for adapting to the host society, they are more likely to marry natives. The enclave effect suggests that educated immigrants are more likely to move out of their ethnic enclaves because, for example, they have larger geographic labor markets. They are, therefore, less likely to 


\begin{tabular}{|c|c|c|c|}
\hline Endogamy & 1 & 2 & 3 \\
\hline \multirow[t]{2}{*}{ Schooling } & -0.010 & 0.018 & 0.012 \\
\hline & $(-1.06)$ & $(1.53)$ & $(1.00)$ \\
\hline \multirow[t]{2}{*}{ Schooling $^{2}$} & 0.000 & -0.002 & -0.001 \\
\hline & $(0.62)$ & $(-3.35)^{* *}$ & $(-2.99)^{* *}$ \\
\hline \multirow{2}{*}{ Size of Ethnic Group } & 3.748 & 3.702 & 3.412 \\
\hline & $(4.50)^{\star *}$ & $(4.54)^{\star \star}$ & $(4.05)^{\star *}$ \\
\hline \multirow[t]{2}{*}{ Size of Ethnic Group ${ }^{2}$} & -7.518 & -7.345 & -7.233 \\
\hline & $(-3.69)^{* *}$ & $(-3.60)^{* *}$ & $(-3.56)^{* *}$ \\
\hline \multirow{2}{*}{$\begin{array}{l}\text { Mean Group Schooling- } \\
\text { Mean Schooling }\end{array}$} & -0.0685 & -0.071 & -0.071 \\
\hline & $(-7.57)^{\star *}$ & $(-10.25)^{\star *}$ & $(-10.17)^{\star *}$ \\
\hline \multirow[t]{2}{*}{ Age } & 0.011 & 0.011 & 0.011 \\
\hline & $(10.39)^{* *}$ & $(10.55)^{\star *}$ & $(10.59)^{\star *}$ \\
\hline \multirow[t]{2}{*}{ Non-English Native Tongue } & 0.161 & 0.161 & 0.161 \\
\hline & $(4.06)^{\star *}$ & $(4.04)^{* *}$ & $(4.06)^{* *}$ \\
\hline \multirow[t]{2}{*}{ Schooling* ${ }_{(\text {(бe-ба) }}$} & & -0.037 & -0.035 \\
\hline & & $(-3.75)^{\star *}$ & $(-3.36)^{\star *}$ \\
\hline \multirow[t]{2}{*}{ Schooling ${ }^{2 *} I_{(\sigma e-\sigma a)}$} & & 0.002 & 0.002 \\
\hline & & $(4.29)^{\star *}$ & $(3.98)^{\star *}$ \\
\hline \multirow[t]{2}{*}{$\mathrm{I}_{(\sigma \mathrm{e}-\sigma a)}$} & & 0.141 & 0.13 \\
\hline & & $(2.71)^{\star *}$ & $(2.30)^{*}$ \\
\hline Schooling ${ }^{\star}$ Group Size & & & $\begin{array}{r}0.081 \\
(2.62)^{\star *}\end{array}$ \\
\hline Schooling ${ }^{2 *}$ Group Size & & & $\begin{array}{r}-0.005 \\
(-4.17)^{\star *}\end{array}$ \\
\hline Observations & 14720 & 14720 & 14720 \\
\hline
\end{tabular}

Table 12: Probit Marginal Effects of Education Level and Variance Interactions on Endogamy for Low Education Ethnicities 


\begin{tabular}{|c|c|c|c|}
\hline Endogamy & 1 & 2 & 3 \\
\hline Schooling & $\begin{array}{r}0.020 \\
(1.15)\end{array}$ & $\begin{array}{l}0.024 \\
(0.95)\end{array}$ & $\begin{array}{r}0.082 \\
(2.14)^{*}\end{array}$ \\
\hline Schooling $^{2}$ & $\begin{array}{r}-.000 \\
(-0.88)\end{array}$ & $\begin{array}{l}-0.001 \\
(-1.06)\end{array}$ & $\begin{array}{r}-0.003 \\
(-2.13)^{*}\end{array}$ \\
\hline Size of Ethnic Group & $\begin{array}{l}0.977 \\
(0.16)\end{array}$ & $\begin{array}{r}1.734 \\
(0.3)\end{array}$ & $\begin{array}{l}14.624 \\
(2.40)^{*}\end{array}$ \\
\hline Size of Ethnic Group ${ }^{2}$ & $\begin{array}{r}30.113 \\
(0.37)\end{array}$ & $\begin{array}{r}19.042 \\
(0.25)\end{array}$ & $\begin{array}{l}0.793 \\
(0.01)\end{array}$ \\
\hline $\begin{array}{l}\text { Mean Group Schooling- } \\
\text { Mean Schooling }\end{array}$ & $\begin{array}{l}0.068 \\
(1.21)\end{array}$ & $\begin{array}{l}0.064 \\
(1.16)\end{array}$ & $\begin{array}{l}0.067 \\
(1.18)\end{array}$ \\
\hline Age & $\begin{array}{l}0.007 \\
(1.74)\end{array}$ & $\begin{array}{c}0.007 \\
(1.68)\end{array}$ & $\begin{array}{l}0.007 \\
(1.67)\end{array}$ \\
\hline Non-English Native Tong & $\begin{array}{r}0.075 \\
(2.07)^{*}\end{array}$ & $\begin{array}{l}0.069 \\
(1.89)\end{array}$ & $\begin{array}{l}0.067 \\
(1.83)\end{array}$ \\
\hline Schooling* ${ }_{(\sigma e-\sigma a)}$ & & $\begin{array}{l}-0.002 \\
(-0.07)\end{array}$ & $\begin{array}{l}-0.002 \\
(-0.06)\end{array}$ \\
\hline Schooling $\left.{ }^{2 *}\right|_{(\sigma e-\sigma a)}$ & & $\begin{array}{l}0.001 \\
(0.36)\end{array}$ & $\begin{array}{l}0.001 \\
(0.35)\end{array}$ \\
\hline $\mathrm{I}_{(\sigma \mathrm{e}-\sigma \mathrm{a})}$ & & $\begin{array}{l}-0.023 \\
(-0.09)\end{array}$ & $\begin{array}{r}-0.025 \\
(-0.1)\end{array}$ \\
\hline Schooling ${ }^{*}$ Group Size & & & $\begin{array}{r}-1.635 \\
(-2.50)^{*}\end{array}$ \\
\hline Schooling ${ }^{2 *}$ Group Size & & & $\begin{array}{l}0.053 \\
(1.87)\end{array}$ \\
\hline Observations & 5389 & 5389 & 5389 \\
\hline
\end{tabular}

Table 13: Probit Marginal Effects of Education Level and Variance Interactions on Endogamy for High Education Ethnicities 
meet possible spouses of their own ethnicity and so, naturally, less likely to marry them. Lastly, the assortative matching effect posits that marriage surplus increases when education levels of husband and wife are similar. This implies that given a costly search process, educated immigrants may be willing to substitute similarities in ethnicity for similarities in education. I develop a model of assortative matching which predicts that an increase in education for immigrants in highly educated ethnicities should actually decrease the likelihood of intermarriage while the opposite is true for men in low education ethnicities.

Using U.S. Census data on second-generation immigrants, I find that indeed the effect of education on endogamy differs by ethnicity suggesting that assortative matching is more important than cultural adaptability when controlling for the enclave effect. In fact, although there is some evidence of the enclave effect, after accounting for the assortative matching effect, the cultural adaptability theory has no support from the data. Second-generation immigrants do exhibit marked preferences for marrying within their ethnicity, but contrary to the predictions of the cultural adaptability effect, these preferences are not related to education, at least not after accounting for migration patterns.

The results from this analysis can be interpreted beyond the realm of marriage decisions; interethnic marriages are a measure of the broader interaction between immigrants, of any generation, and natives. Presumably, human capital affects intermarriages in the same ways it affects any association between people of different ethnicities. Given the abundant literature on the importance of networks in determining wages, employment rates, occupational status, and schooling levels, the social integration of immigrants to the host society plays an important role in their economic integration.

If the social integration of immigrants is in fact a policy goal, the conclusions from this paper can provide some insights into both immigration and education policy. Given the correlation in ed- 
ucation levels between parents and their offspring, the fact that education affects second-generation endogamy mainly through assortative matching has implications towards which immigrant groups can most quickly assimilate into U.S. society. Specifically, it implies that those ethnic groups with average education levels closest to the U.S. level can more easily integrate into U.S. society. In fact, given the evidence that all else equal, immigrants prefer to marry within their ethnicity, it may be even more beneficial to give priority to the people with education levels most similar to U.S. average levels but that are in the least educated ethnic groups. Because of the greater scarcity of potential spouses of both the same ethnicity and education level, these immigrants would be most likely to associate with natives. ${ }^{20}$

The role of human capital in intermarriage decisions also provides an indirect avenue through which education policies could catalyze the social integration process of immigrants and their children. The fact that education works mainly through assortative matching suggests that it is the immigrants at the bottom of the education distribution that have the most to gain from education policies. For example, because education only has a positive effect on interethnic marriage rates for low education ethnicities, policies aimed at increasing high school graduation rates would be more beneficial than policies providing scholarships for graduate schools. In the end, many insights into the assimilation process can be gained from studying the marriage decisions of immigrants and their descendents.

\footnotetext{
${ }^{20}$ Of course, if this policy were implemented, then in the long run, the low education ethnic group could no longer be considered a low education group at least in the U.S.
} 


\section{References}

[1] Angrist, Joshua. "How do Sex Ratios Affect Marriage Markets and Labor Markets? Evidence from America's Second Generation." Quarterly Journal of Economics. Vol. 117, Issue 3, (2002), 997-1038.

[2] Barro, Robert and McCleary, Rachel, "Religion and Economic Growth" (May 2003). NBER Working Paper No. W9682. http://ssrn.com/abstract=406054

[3] Battu, H., Mwale, M. and Y. Zenou. "Do Oppositional Identities Reduce Employment for Ethnic Minorities." IZA Discussion Paper, No. 721.

[4] Becker, Gary. A Treatise on the Family. Harvard University Press. Cambridge, MA (1981).

[5] Bisin, Alberto and Thierry Verdier. "Beyond The Melting Pot': Cultural Transmission, Marriage, and the Evolution of Ethnic and Religious Traits." Quarterly Journal of Economics. Vol. 115, Issue 3, (2000), 955-988.

[6] Bisin, Alberto, Giorgio Topa and Thierry Verdier. "An Empirical Analysis of Religious Homogamy and Socialization in the U.S." Journal of Political Economy, Vol. 112, Issue 3, (2004), $615-64$.

[7] Borjas, George J. "Ethnic Capital and Intergenerational Mobility." The Quarterly Journal of Economics. Vol 107, Issue 1, (1992), 123-150.

[8] Borjas, George J. "The Intergenerational Mobility of Immigrants." Journal of Labor Economics. Vol 11, Issue 1, (1993), 113-135.

[9] Borjas, George J. "Ethnicity, Neighborhoods, and Human Capital Externalities." American Economic Review, Vol 85, Issue 3, (1995), 365-390. 
[10] Borjas, George J. "To Ghetto or Not to Ghetto: Ethnicity and Residential Segregation." Journal of Urban Economics, Vol 44, (1998), 228-253.

[11] Card, David, John DiNardo, and Eugena Estes. "The More Things Change: - and the Children of Immigrants in the 1940s, the 1970s, and the 1990s." Issues in the Economics of Immigration, National Bureau of Economic Research Conference Report, (1999).

[12] Chiswick, Barry. "Sons of Immigrants: Are They at an Earnings Disadvantage?" American Economic Review, (1977), 376-380.

[13] Chiswick, Barry. "The Effect of Americanization on the Earnings of Foreign-Born Men." Journal of Political Economy. Vol 86, Issue 5, (1978), 897-922.

[14] Chiswick, Barry and Noyna DebBurman. "Educational Attainment: Analysis by Immigrant Generation." Economics of Education Review, Vol. 23, Issue 4, (2004), 361-379.

[15] Cohen, Steven Martin. "Socioeconomic Determinants of Intraethnic Marriage and Friendship." Social Forces. Vol 55, Issue 4, (1977), 997-1010.

[16] Davis, Kingsley and Pietronella van den Oever. "Demographic Foundations of New Sex Roles." Population Development Review. Vol. 8, (1982), 309-340.

[17] Duncan, Brian and Stephen Trejo. "Ethnic Identification, Intermarriage, and Unmeasured Progress by Mexican Americans." NBER Website. Monday, December 12, 2005. $<$ http://www.nber.org/papers/w11423>.

[18] Edin, Per-Anders; Fredriksson, Peter; Aslund, Olof. "Ethnic Enclaves and the Economic Success of Immigrants-Evidence from a Natural Experiment." Quarterly Journal of Economics. Vol.118, Issue 1 (2003), 329-57. 
[19] "The Foreign Born Population in the United States: 2003." Current Population Reports. Population Characteristics. Series P20-551, (2004).

[20] Gordon, Milton. Human Nature, Class, and Ethnicity. New York: Oxford University Press. (1964).

[21] Hyman, Herbert H. and Charles R. Wright. Education's Lasting Influence on Values. Chicago: University of Chicago Press (1979).

[22] Jasso, Guilermina and Mark Rosenzweig. The New Chosen People : Immigrants in the United States. New York : Russell Sage Foundation. (1990).

[23] Jasso, Guilermina, Douglas Massey, Mark Rosenzweig, and James Smith. "Assortative Mating Among Married New Legal Immigrants to the United States: Evidence From the New Immigrant Survey Pilot, " International Migration Review. Vol 34, Issue 2, (2000), 443-459.

[24] Kalmijn, Matthijs. "Shifting boundaries: Trends in Religious and Educational Homogamy." American Sociological Review, Vol. 56, (1991), 786-800.

[25] Kalmijn, Matthijs. "Spouse Selection among Children of European Immigrants: A Comparison of Marriage Cohorts in the 1960 Census." International Migration Review. Vol 27, Issue 1, (1993), 51-78.

[26] Kalmijn, Matthijs, Paul M. de Graaf and Jacques P. G. Janssen. "Intermarriage and the Risk of Divorce in the Netherlands: The Effects of Differences in Religion and in Nationality." Population Studies. Vol. 59, Issue 1, (2005), 71-85.

[27] Kantarevic, Jasmin. "Interethnic Marriages and Economic Assimilation of Immigrants." IZA Discussion Paper, No. 1142.

[28] Kohn, Melvin L. Class and Conformity. Chicago: University of Chicago Press, (1977). 
[29] Lam, David. "Marriage Markets and Assortative Mating with Household Public Goods: Theoretical Results and Empirical Implications." The Journal of Human Resources. Vol. 23, Issue 4, (1988), 462-487.

[30] Lichter, Daniel T. and Zhenchao Qian. "Measuring Marital Assimilation: Intermarriage Among Natives and Immigrants." Social Science Research Vol. 30, (2001), 289-312.

[31] Lieberson Stanley and Mary Waters. From Many Strands: Ethnic and Racial Groups in Contemporary America. Population of the United States in the 1980s, a Census Monograph Series. New York: Russell Sage Foundation, (1988).

[32] Meng, Xin and Robert G. Gregory. "Intermarriage and the Economic Assimilation of Immigrants." Journal of Labor Economics. Vol. 23, Issue 1, (2005), 135-75.

[33] Munshi, Kaivan. "Networks in the Modern Economy: Mexican Migrants in the U.S. Labor Market." Quarterly Journal of Economics, Vol 118, Issue 2, (2003), 549-597.

[34] Ramakrishnan, S. Karthick. "Second-Generation Immigrants? The '2.5 Generation' in the United States." Social Science Quarterly, Vol 85, Issue 2, (2004), 380-399.

[35] Robinson, John P. How Americans Use Their Time. New York: Praeger (1977).

[36] Ruggles, Steven and Matthew Sobek et al. Integrated Public Use Microdata Series: Version 3.0 Minneapolis: Historical Census Projects, University of Minnesota, 2003.

[37] Stevens, Gillian and Gray Swicegood. "The Linguistic Context of Ethnic Endogamy." American Sociological Review. Vol 52, Issue 1, (1987), 73-82.

[38] Wong, Linda. "Why Do Only 5.5\% of Black Men Marry White Women?" International Economic Review. Vol 44, Issue 3, (2003), 803-806. 


\section{Appendix}

\section{A Proof of Proposition 2}

Proposition 2: An increase in the man's education results in a shift to the right of the accepted values of education of possible wives.

$$
1-\frac{d R / d h}{2 \sqrt{-R}}>0 \text { and } 1+\frac{d R / d h}{2 \sqrt{-R}}>0
$$

Proof: To prove that $1-\frac{d R / d H}{2 \sqrt{-R}}$ and $1+\frac{d R / d H}{2 \sqrt{-R}}$ are both positive, we need only show that $|d R / d H|<2 \sqrt{-R}$. This implies that $|d R / d H|^{2}-(2 \sqrt{-R})^{2}<0$. Since $R=p\left(-E\left[\left(h_{e}^{w}-h_{i}\right)^{2}\right]\right)+$ $(1-p)\left(-E\left[\left(h_{a}^{w}-h_{i}\right)^{2}\right]\right), d R / d H=2\left(p \bar{h}_{e}^{w}+(1-p) \bar{h}_{a}^{w}-h\right)$. Thus,

$$
\begin{aligned}
\left(\frac{d R}{d H}\right)^{2}= & 4\left[p^{2} h_{e}^{w 2}+2 p \bar{h}_{e}^{w} \bar{h}_{a}^{w}-2 p^{2} \bar{h}_{e}^{w} \bar{h}_{a}^{w}+\bar{h}_{a}^{w 2}-2 p \bar{h}_{a}^{w 2}+p^{2} \bar{h}_{a}^{w 2}\right. \\
& \left.-2 p \bar{h}_{e}^{w} h-2 \bar{h}_{a}^{w} h+2 p \bar{h}_{a}^{w} h+h^{2}\right]
\end{aligned}
$$

Expanding $-R$, we arrive at

$$
\begin{aligned}
-R= & E\left[\left(h_{e}^{w}-h_{i}\right)^{2}\right]+(1-p)\left(-E\left[\left(h_{a}^{w}-h_{i}\right)^{2}\right]\right)+\tau \\
= & \left.p\left(\sigma_{e}^{2}+\bar{h}_{e}^{w}\right)+(1-p)\left(\sigma_{a}^{2}+\bar{h}_{a}^{w}\right)-2 h\left(p \bar{h}_{e}^{w}+(1-p) \bar{h}_{a}^{w}\right]\right)+h^{2}+\tau \\
= & p \sigma_{e}^{2}+p \bar{h}_{e}^{w_{2}}-2 p \bar{h}_{e}^{w} h+p h^{2}+(1-p) \sigma_{a}^{2}+\bar{h}_{a}^{w_{2}}-p \bar{h}_{a}^{w}- \\
& 2 \bar{h}_{a}^{w} h+2 p \bar{h}_{a}^{w} h+h^{2}-p h^{2}+\tau
\end{aligned}
$$

So,

$$
|d R / d H|^{2}-(2 \sqrt{-R})^{2}=\left(\frac{d R}{d H}\right)^{2}-4(-R)
$$




$$
\begin{aligned}
& =4\left[p(1-p)\left(-\bar{h}_{e}^{w}+\bar{h}_{a}^{w}\right)\left(\bar{h}_{e}^{w}-\bar{h}_{a}^{w}\right)-p \sigma_{e}^{2}-(1-p) \sigma_{a}^{2}-\tau\right] \\
& <0
\end{aligned}
$$

Since $2 \sqrt{-R}$ is always positive, the sign of $\frac{d R / d H}{2 \sqrt{-R}}$ depends solely on $d R / d H$. Since, $d R / d H=$ $2\left(p \bar{h}_{e}^{w}+(1-p) \bar{h}_{a}^{w}-h\right)$, this means that $\frac{d R / d H}{2 \sqrt{-R}} \in(-1,0)$ if $h<p \bar{h}_{e}^{w}+(1-p) \bar{h}_{a}^{w} \frac{d R / d H}{2 \sqrt{-R}} \in(0,1)$ if $h>p \bar{h}_{e}^{w}+(1-p) \bar{h}_{a}^{w}$, and $\frac{d R / d H}{2 \sqrt{-R}}=0$ if $h=p \bar{h}_{e}^{w}+(1-p) \bar{h}_{a}^{w}$. Therefore, $1-\frac{d R / d H}{2 \sqrt{-R}}$ and $1+\frac{d R / d H}{2 \sqrt{-R}}$ are always positive.

\section{B Proof of Proposition 3}

Proposition 3: Assuming $f_{e}$ and $f_{a}$ are the same unimodal distribution with different means but the same variance, $T=0$, and $\bar{h}_{e}^{w}<\bar{h}_{a}^{w}$, then there exists an $h^{*}\left(p, \sigma^{2}, \bar{h}_{a}^{w}, \bar{h}_{e}^{w}\right)$ such that if either $p>1 / 2$ and $h>h^{*}, p<1 / 2$ and $h<h^{*}$, or if $p=1 / 2$, an increase in $h$ will yield a decrease in the probability of marrying within ethnicity.

$$
\frac{d \operatorname{Pr}(\text { Endogamy })}{d h}<0 \text { if } \bar{h}_{e}^{w}<\bar{h}_{a}^{w}
$$

If $\bar{h}_{e}^{w}>\bar{h}_{a}^{w}$, the opposite is true. That is, if either $p<1 / 2$ and $h>h^{*}, p>1 / 2$ and $h<h^{*}$, or if $p=1 / 2$, then an increase in $h$ will yield an increase in the probability of marrying within ethnicity.

$$
\frac{d \operatorname{Pr}(\text { Endogamy })}{d h}>0 \text { if } \bar{h}_{e}^{w}>\bar{h}_{a}^{w}
$$

Proof: Recall that $\operatorname{Pr}($ Endogamy $)=p+p(1-p)\left\{\left[F_{e}\left(L^{u}\right)-F_{e}\left(L^{l}\right)\right]-\left[F_{a}\left(L^{u}\right)-F_{a}\left(L^{l}\right)\right]\right\}$, and thus,

$$
\begin{aligned}
\frac{d \operatorname{Pr}(\text { Endogamy })}{d h}= & p(1-p)\left(\frac{d L^{u}}{d h}\right)\left[f_{e}\left(L^{u}\right)-f_{a}\left(L^{u}\right)\right]- \\
& p(1-p)\left(\frac{d L^{l}}{d h}\right)\left[f_{e}\left(L^{l}\right)-f_{a}\left(L^{l}\right)\right]
\end{aligned}
$$


By Proposition 2, we know that $d L^{u} / d h$ and $d L^{l} / d h$ are both positive meaning that the limits of the acceptance region always shift to the right with an increase in education. Thus, a sufficient condition $^{21}$ for the signability of equation $9 A$ relies on the signability of $f_{e}\left(L^{u}\right)-f_{a}\left(L^{u}\right)$ and $f_{e}\left(L^{l}\right)-f_{a}\left(L^{l}\right)$. If $f_{e}$ and $f_{a}$ are the same unimodal distribution with different means, then we need only show that the acceptance limits, $L^{l}$ and $L^{u}$, lie on opposite sides of the intersection of the two distributions. To see why, look at Figure 3. If the limits lie on opposite sides of the intersection of $f_{e}$ and $f_{a}$, the upper limit will always be to the right of the intersection and the lower limit to the left. This means that if $\bar{h}_{e}^{w}<\bar{h}_{a}^{w}$, then $f_{e}\left(L^{u}\right)-f_{a}\left(L^{u}\right)<0$ and $-f_{e}\left(L^{l}\right)+f_{a}\left(L^{l}\right)<0$ and so we can say that $\operatorname{Pr}($ Endogamy $) / d h<0$. Similarly, if $\bar{h}_{e}^{w}>\bar{h}_{a}^{w}$, then $f_{e}(U)-f_{a}(U)>0$ and $-f_{e}(L)+f_{a}(L)>0$ and so $\operatorname{Pr}($ Endogamy $) / d h>0$. Naturally, if $\bar{h}_{e}^{w}=\bar{h}_{a}^{w}$, then $f_{e}\left(L^{u}\right)-f_{a}\left(L^{u}\right)=0$ and $-f_{e}\left(L^{l}\right)+f_{a}\left(L^{l}\right)=0$ and thus $\operatorname{Pr}($ Endogamy $) / d h=0$.

The remainder of the proof proceeds in two parts. In Part 1 , it is shown that if $p=1 / 2$, the $\operatorname{Pr}($ Endogamy $) / d h<0$ if $\bar{h}_{e}^{w}<\bar{h}_{a}^{w}$ and $\operatorname{Pr}($ Endogamy $) / d h>0$ if $\bar{h}_{e}^{w}>\bar{h}_{a}^{w}$ When $p \neq$ $1 / 2$, a sufficient condition on $h$ is found which guarantees these relationships between $h$ and the $\operatorname{Pr}($ Endogamy $)$.

PART 1 : Because the utility function is strictly concave, to do this, we need only show that utility from the level of education where the two pdfs intersect, $U\left(\frac{\bar{h}_{e}^{w}+\bar{h}_{a}^{w}}{2}\right)$ is greater than the reservation utility, $R$. Because of the shape of the utility function, this condition is enough to guarantee that the maximum accepted education level lies to the right of the intersection and the minimum always lies to the left. Evaluating utility from the level of education at the intersection

\footnotetext{
${ }^{21}$ The necessary and sufficient condition depends on the functional forms of $f_{e}$ and $f_{a}$ and thus it is not provided in this paper. Moreover, attempts to solve for this condition proved computationally difficult with even a basic normal distribution.
} 
of the two distributions, we arrive at

$$
\begin{aligned}
U\left(\frac{\bar{h}_{e}^{w}+\bar{h}_{a}^{w}}{2}\right) & =-\left[\frac{\bar{h}_{e}^{w}+\bar{h}_{a}^{w}}{2}-h\right]^{2} \\
& =-\frac{1}{4} \bar{h}_{e}^{w 2}-\bar{h}_{e}^{w} \bar{h}_{a}^{w}+\frac{1}{2} \bar{h}_{e}^{w} \bar{h}_{a}^{w}-\frac{1}{4} \bar{h}_{a}^{w}+h \bar{h}_{e}^{w}+h \bar{h}_{a}^{w}-h^{2}
\end{aligned}
$$

Recall from the proof of Proposition 2 that the reservation utility equation can be written,

$$
R=-p\left(\sigma_{e}^{2}+\bar{h}_{e}^{w 2}\right)-(1-p)\left(\sigma_{a}^{2}+\bar{h}_{a}^{w}\right)+2 h\left(p \bar{h}_{e}^{w}+(1-p) \bar{h}_{a}^{w}\right)-h^{2}-\tau
$$

Thus, if $p=\frac{1}{2}$,

$$
\begin{aligned}
U\left(\frac{\bar{h}_{e}^{w}+\bar{h}_{a}^{w}}{2}\right)-R & =\frac{1}{4}\left(\bar{h}_{e}^{w}-\bar{h}_{a}^{w}\right)^{2}+\frac{1}{2} \sigma_{e}^{2}+\frac{1}{2} \sigma_{a}^{2}+\tau \\
& >0
\end{aligned}
$$

Since this proves that $L^{l}$ and $L^{u}$ lie on opposite sides of the intersection of the education distributions equation $9 \mathrm{~A}$ is signable in the way discussed above.

PART 2: To solve for that level of education which guarantees that acceptance limits lie on opposite sides of the intersection of the education distributions, we simply set $L^{u}=\mu$ and solve for $h$. This $h$ we call $h^{*}$. Because of the symmetry of $L^{u}$ and $L^{l}$, this yields the same $h^{*}$ as setting $L^{l}=\mu$. Thus, one can see that

$$
h^{*}=\frac{\frac{1}{4}\left[-4 p \sigma_{e}^{2}-4 p \bar{h}_{e}^{w}+4 \sigma_{a}^{2}+3 \bar{h}_{a}^{w_{2}}-4 p \sigma_{a}^{2}-4 p \bar{h}_{a}^{w}-2 \bar{h}_{a}^{w}-\bar{h}_{e}^{w 2}\right]}{\left(\bar{h}_{e}^{w}-\bar{h}_{a}^{w}\right)(2 p-1)}
$$

It is easy to see from this equation that, consistent with PART 1 of this proof, if $p=1 / 2, h^{*}$ does not exist. 
If $\bar{h}_{e}^{w}<\bar{h}_{a}^{w}$ and $p>1 / 2$, then by construction of $h^{*}, L^{u}=\mu$ and so $h^{*}<\mu$ and $L^{l}<\mu$. Since $L^{l}<\mu$ and $\bar{h}_{e}^{w}<\bar{h}_{a}^{w}, f_{e}\left(L^{l}\right)>f_{a}\left(L^{l}\right)$. Since $L^{u}=\mu, f_{e}\left(L^{u}\right)=f_{a}\left(L^{u}\right)$ and so the second component of equation (9A) drops out. If $h>h^{*}, L^{u}>\mu$. and so $f_{e}\left(L^{u}\right)<f_{a}\left(L^{u}\right)$. Thus, by the discussion above, all of the components of equation (9A) are signable if $h \geq h^{*}$. Specifically, if $p>1 / 2$ and $\bar{h}_{e}^{w}<\bar{h}_{a}^{w}$, then for any $h \geq h^{*}, d \operatorname{Pr}($ Endogamy $) / d h<0$.

If $\bar{h}_{e}^{w}<\bar{h}_{a}^{w}$ and $p<1 / 2$, then by construction of $h^{*}, L^{l}=\mu$ and so $h^{*}>\mu$ and $L^{u}>\mu$. Since $L^{u}>\mu$ and $\bar{h}_{e}^{w}<\bar{h}_{a}^{w}, f_{e}\left(L^{u}\right)<f_{a}\left(L^{u}\right)$. Since $L^{l}=\mu, f_{e}\left(L^{l}\right)=f_{a}\left(L^{l}\right)$, and so the first component of equation (9A) drops out. If $h<h^{*}, L^{l}<\mu$ and so $f_{e}\left(L^{u}\right)<f_{a}\left(L^{u}\right)$. Thus, all of the components of equation (9A) are signable if $h<h^{*}$. Specifically, if $p<1 / 2$ and $\bar{h}_{e}^{w}<\bar{h}_{a}^{w}$, then for any $h \leq h^{*}$, $d \operatorname{Pr}($ Endogamy $) / d h<0$.

The proofs work exactly the same way when $\bar{h}_{e}^{w}>\bar{h}_{a}^{w}$. 